\title{
Oxidative Cyclizations in a Nonpolar Solvent Using Molecular Oxygen and Studies on the Stereochemistry of Oxypalladation
}

\author{
Raissa M. Trend, Yeeman K. Ramtohul, and Brian M. Stoltz.* \\ The Arnold and Mabel Beckman Laboratories of Chemical Synthesis, Division of Chemistry and \\ Chemical Engineering, California Institute of Technology, 1200 E. California Blvd., MC 164-30, \\ Pasadena, CA 91125
}

\begin{abstract}
Oxidative cyclizations of a variety of heteroatom nucleophiles onto unactivated olefins are catalyzed by palladium(II) and pyridine in the presence of molecular oxygen as the sole stoichiometric oxidant in a nonpolar solvent (toluene). Reactivity studies of a number of $N$-ligated palladium complexes show that chelating ligands slow the reaction. Nearly identical conditions are applicable to five different types of nucleophiles: phenols, primary alcohols, carboxylic acids, a vinylogous acid, and amides. Electron-rich phenols are excellent substrates, and multiple olefin substitution patterns are tolerated. Primary alcohols undergo oxidative cyclization without significant oxidation to the aldehyde, a fact that illustrates the range of reactivity available from various Pd(II) salts under differing conditions. Alcohols can form both fused and spirocyclic ring systems, depending on the position of the olefin relative to the tethered alcohol; the same is true of the acid derivatives. The racemic conditions served as a platform for the development of an enantioselective reaction. Experiments with stereospecifically deuterated primary alcohol substrates rule out a "Wacker-type" mechanism involving anti oxypalladation and suggest that the reaction proceeds by syn oxypalladation for both mono- and bidentate ligands. In contrast, cyclizations of deuterium-labeled carboxylic acid substrates undergo anti oxypalladation.
\end{abstract}

\section{INTRODUCTION}

Oxidation is one of the most fundamental and important processes in nature. It has also become one of the most effective ways for chemists to induce asymmetry in organic transformations for the production of enantioenriched materials. ${ }^{1}$ Most enantioselective oxidations involve the transfer of a heteroatom, commonly oxygen, to a substrate in a manner analogous to that of oxygenase metalloenzymes. In contrast, there is a significant lack of asymmetric two-electron oxidations that do not involve heteroatom transfer. This second mode of oxidation is similar to oxidase-type enzymatic reactions for which oxygen atoms instead act as electron and proton acceptors in substrate oxidation.

The ability of palladium $(\mathrm{Pd})$ to serve as both a nucleophile $(\mathrm{Pd}(0))$ and an electrophile $(\mathrm{Pd}$ (II)) has led to an explosion in $\operatorname{Pd}(0)$-catalyzed reactions that have become indispensable to organic chemistry. ${ }^{2}$ This property has also led to the development of racemic oxidase-type reactions that feature electrophilic Pd(II), some examples of which are shown in Figure 1, although they are much less prevalent. ${ }^{3}$ Such reactions require the recycling of $\operatorname{Pd}(0)$ to $\mathrm{Pd}(\mathrm{II})$ by a stoichiometric oxidant. Ideally, such a process would take advantage of the most abundant and inexpensive oxidant, molecular oxygen $\left(\mathrm{O}_{2}\right)$. In fact, one of the early systems developed for the catalytic oxidation of secondary alcohols by $\mathrm{Pd}(\mathrm{II})$ employed $\mathrm{O}_{2}$ directly as the only 
stoichiometric oxidant. ${ }^{4}$ The use of DMSO as solvent also has enabled racemic $\mathrm{O}_{2}$-coupled $\mathrm{Pd}(\mathrm{II})$-catalyzed oxidative cyclizations of olefin-appended nucleophiles such as phenols, alcohols, acids and tosylamides, as well as alcohol oxidations to ketones and aldehydes. ${ }^{5}$ Two other reoxidation systems include the traditional Wacker process that employs a copper cocatalyst in the presence of $\mathrm{O}_{2}$, and the use of the organic oxidant benzoquinone as a stoichiometric oxidant. Racemic cyclization reactions have also been developed using these reoxidants. 6,7

Despite these advances in racemic $\mathrm{Pd}(\mathrm{II})$-catalyzed oxidation reactions, many do not meet the ideal criteria for enantioselective reactions of employing only $\mathrm{O}_{2}$ as the stoichiometric oxidant in a non-coordinating solvent. Instead, the necessary use of cocatalysts, organic oxidants or DMSO has complicated the development of asymmetric oxidase-type reactions. For example, the use of copper/ $\mathrm{O}_{2}$ introduces a secondary catalytic cycle and another metal that could compete with Pd for the chiral ligand. The benzoquinone system requires the removal of stoichiometric amounts of organic compounds 8 and benzoquinone itself can act as a ligand. 9,10 In addition, DMSO is a highly donating solvent that could interfere with the coordination of a chiral ligand to Pd. Despite the obstacles presented by the traditional oxidation systems, seminal works by Hosokawa and Murahashi, ${ }^{11}$ Hayashi, ${ }^{12}$ Sasai $^{13}$ and Bäckvall ${ }^{9}$ established the potential of enantioselective $\mathrm{Pd}(\mathrm{II})$-catalyzed oxidative cyclizations and dialkoxylations. 14

With the requirement that $\mathrm{O}_{2}$ be the only stoichiometric oxidant, we began to address the lack of enantioselective oxidase-type catalysis with the development of the Pd(II)-catalyzed asymmetric dehydrogenation of secondary alcohols illustrated in Figure $2 .{ }^{15,16}$ This oxidation effects a kinetic resolution to provide enantioenriched alcohol, and was the first example of an asymmetric oxidase-type reaction in that it employs $\mathrm{O}_{2}$ as the terminal oxidant. The basis for this chemistry was another racemic Pd(II)-catalyzed alcohol oxidation reported in 1999 by Uemura and coworkers. ${ }^{17}$ Significantly, the reaction used only $\mathrm{O}_{2}$ in a non-cooridnating solvent (toluene), and was accelerated by the presence of a ligand (pyridine). We subsequently initiated an effort to apply our enantioselective alcohol oxidation to the development of asymmetric versions of reactions such as those shown in Figure 1. In line with this goal, we recently communicated the extension of Uemura's conditions to the cyclizations of heteroatoms and electron-rich indoles onto pendant olefins, as well as an asymmetric version of the former reaction. ${ }^{18,19}$ This work established that heteroatom-olefin cyclizations that use $\mathrm{O}_{2}$ as the sole oxidant could be amenable to asymmetric catalysis. We now report the full details regarding the development of these racemic and asymmetric heterocyclizations, an expanded substrate scope for both, and deuterium-labeling studies that establish the stereochemistry of oxypalladation for two types of substrates. On the basis of our results, we offer a rationale for the difficulty in developing the asymmetric reaction in this system specifically. As recent work by Hayashi, Wolfe, Sanford, White, Stahl, Sigman and others has also shown, our studies further demonstrate that oxidase-type catalysis by $\mathrm{Pd}(\mathrm{II})$ is both advantageously versatile in terms of reactivity and frustratingly promiscuous in terms of mechanism.

\section{RESULTS AND DISCUSSION}

\section{Reaction development}

The effect of palladium $\mathrm{X}^{-}$ligand, exogenous base and nitrogen-containing ligand on reaction rate-Our initial aim was to establish Pd(II)-catalyzed conditions for racemic aerobic cyclizations to which a chiral ligand eventually could be introduced. Thus, we began our investigation of aerobic oxidative cyclizations with 2-(1,2-dimethyl-1-propenyl) phenol (1) using a variety of palladium(II) salts, pyridine, $\mathrm{O}_{2}$, and MS3 $\mathrm{A}$ in toluene at $80{ }^{\circ} \mathrm{C}$ (Table 1). These conditions are modeled after Uemura's alcohol oxidation conditions, ${ }^{17 \mathrm{a}}$ 
which, as stated above, were also employed as a starting point for our oxidative kinetic resolution chemistry. ${ }^{15 \mathrm{a}}$ Surprisingly, $\mathrm{Pd}(\mathrm{nbd}) \mathrm{Cl}_{2}$, which is the most effective catalyst for the kinetic resolution chemistry, was ineffective for the cyclization of $\mathbf{1}$ to dihydrofuran $\mathbf{2}$ (entry 1). Treatment of 1 with a range of palladium(II) salts (entries 1-4) led to the discovery that the electron-deficient palladium(II) trifluoroacetate $\left(\operatorname{Pd}(\mathrm{TFA})_{2}\right)$ was most effective for producing 2 in good yield after reasonable reaction time (entry 4). A number of exogenous bases were examined with the hope that proton consumption would accelerate the reaction (not shown, see Supporting Information). Sodium carbonate exerts the most positive effect to give 95\% yield in under 30 minutes (entry 5). $\operatorname{Pd}(0)$ sources were found to be poor catalysts for the reaction: $\mathrm{Pd}_{2}(\mathrm{dba})_{3}$ resulted in the formation of a small amount of product, along with palladium black (entry 6), and palladium black itself gave no reaction (entry 7). No cyclization occurred in the absence of any palladium (entry 8). $\mathrm{O}_{2}$ is necessary for good reactivity, although there appears to be a background reaction that leads to cyclization since the product is formed in greater than 5\% yield (entry 9). The presence of 30 equivalents of elemental mercury slowed the cyclization, but did not prevent reaction altogether, which contraindicates colloidal Pd or $\mathrm{Pd}$ nanoparticles as the relevant catalytic species (entry 10). ${ }^{20}$

Although pyridine had been a competent ligand during our optimization studies, we carried out a small ligand screen of other nitrogen-containing ligands. ${ }^{21}$ Each $\mathrm{L}_{\mathrm{n}} \mathrm{Pd}(\mathrm{TFA})_{2}$ complex was synthesized separately and characterized, rather than generated in situ, in order to limit uncertainty regarding the catalyst or catalyst precursor. Reactions were performed with no additive, $40 \mathrm{~mol} \%$ excess ligand, and both excess ligand and $\mathrm{Na}_{2} \mathrm{CO}_{3}$. As shown in Table 2, substituted pyridyls that are less coordinating than pyridine, whether due to electronic or steric reasons, result in the precipitation of Pd black. Bidentate nitrogen-containing ligands such as 2,2'-dipyridyl (entry 6), 4,7-dimethyl-1,10-phenanthroline (entry 7), TMEDA (entry 10), or TMPDA (entry 11) significantly slow the reaction. Weak alkyl amine donors result in the precipitation of Pd black (entries 8-9,11). Although some rate enhancement was observed for the nicotinate derivatives (entries 4 and 5), pyridine offered the best combination of reactivity, catalyst stability, and availability.

Cyclizations of phenols and primary alcohols-Under our optimized conditions, oxidative cyclization of a variety of substituted phenols occurs readily with $5 \mathrm{~mol} \% \mathrm{Pd}$ (TFA $)_{2}, 20$ mol\% pyridine, 2 equiv $\mathrm{Na}_{2} \mathrm{CO}_{3}$ and $500 \mathrm{mg} 3 \AA$ molecular sieves $/ \mathrm{mmol}$ substrate at $0.1 \mathrm{M}$ concentration in toluene under a balloon of oxygen (Table 3 ). Workup involves simple filtration through a pad of silica gel. Cyclizations of electron-rich phenols are facile and provide excellent yields in under $30 \mathrm{~min}$ (entries 1-4, 7-10). An electron deficient phenol (9) serves as an excellent substrate as well, albeit with slower reaction time (entry 5). In contrast, a $p$ bromo-substituted substrate (11, entry 6) appears to undergo alternate reaction pathways leading to decomposition, possibly via oxidative addition to $\mathrm{Pd}(0)$. Cyclization onto a tetrasubstituted olefin (21) proceeds in good yield (entry 11), as does cyclization of a disubstituted olefin (23, entry 12). A dihydropyran (26) is available under identical conditions (entry 13). Finally, high yields and reasonable rates persist with reduced catalyst loading (2 mol\%, entry 14). For terminal olefin substrate $\mathbf{2 7}$, reaction does not take place, most likely because exo cyclization occurs that then leaves no $\beta$-hydrogens to be eliminated from the presumed Pd-alkyl intermediate.

In addition to phenols, we have investigated primary alcohol/olefin oxidative cyclizations. Remarkably, these reactions proceed to the heterocyclic ethers with, in most cases, little or no oxidation to the aldehyde under our optimized conditions (Table 4). In addition to benzyl alcohol 28, cyclopentene (30 and 32) and cyclohexene (34) derivatives provide moderate to excellent yields of spirocycles $(\mathbf{3 1})$ and fused ring systems $(\mathbf{3 3}, \mathbf{3 5})$. The mode of oxidative reactivity - cyclization versus alcohol oxidation - appears dependent not only on the substrate 
(i.e., primary vs. secondary alcohols) but also on the specific palladium source (cf. Uemura's work $^{17}$ ).

\section{Cyclizations of carboxylic acids and derivatives}

A range of carboxylic acid and carboxylic acid derivatives were synthesized and subjected to our optimized conditions. For some carboxylic acid derivatives $(\mathbf{3 6}, \mathbf{3 8}, \mathbf{4 0}, \mathbf{4 4})$, the addition of an inorganic base was found to be unnecessary, and exposure simply to $5 \mathrm{~mol} \% \mathrm{Pd}$ (TFA) $)_{2}, 20 \mathrm{~mol} \%$ pyridine, $500 \mathrm{mg} \mathrm{MS} 3 \AA / \mathrm{mmol}$ substrate and 1 atm $\mathrm{O}_{2}$ in toluene at $80{ }^{\circ} \mathrm{C}$ led to the oxidatively cyclized products (Table 5, entries 1-3,5). Benzoic acids (36) and amides $(\mathbf{3 8}, \mathbf{4 0})$ are cyclized in good to excellent yields (entries 1-3). A $\beta$-keto ester (42) undergoes cyclization as a vinylogous acid to form a heterocycle (43) rather than a carbocycle (entry 4). Primary acid derivatives react to form spirocycles (45) or fused bicyclic systems (47 and 49), depending on the position of the olefin (entries 5-7). The cyclization of derivatives $\mathbf{4 6}$ and 48 is more facile with double the catalyst loading and is accelerated by the presence of 2 equiv $\mathrm{Na}_{2} \mathrm{CO}_{3}$.

\section{Reaction scope and limitations}

The high yields, usually brief reaction times, and range of substrates that are characteristic of this aerobic Pd-catalyzed oxidative cyclization demonstrate the utility of the simple reaction conditions - Pd, ligand, base, $\mathrm{O}_{2}$, and solvent. Nearly identical conditions are applicable to five different types of nucleophiles: phenols, primary alcohols, carboxylic acids, a vinylogous acid, and amides. Electron-rich phenols are excellent substrates, and multiple olefin substitution patterns are tolerated. Primary alcohols undergo oxidative cyclization without significant oxidation to the aldehyde, a fact that illustrates the range of reactivity available from various $\mathrm{Pd}(\mathrm{II})$ salts under differing conditions. In addition to the cyclization of a benzylic alcohol, non-benzylic alcohols can form both fused and spirocyclic ring systems; the same is true of the acid derivatives. Undoubtedly the range of alcohol substrates could be increased. 22 While phenol/olefin, alcohol/olefin, 5 a,6a,23 and carboxylic acid/olefin $5 \mathrm{c}, 24,25$ cyclizations have been achieved before under $\mathrm{Pd}(\mathrm{II}) /$ oxidant catalysis, our conditions differentiate themselves by meeting the criteria for extension to an asymmetric version: simplicity, capacity to accommodate a chiral ligand, and active catalysis in a non-coordinating solvent. Without a system of this type the development of a direct aerobic asymmetric cyclization would be less feasible.

\section{Elaboration of racemic conditions to an asymmetric version}

A number of chiral ligands were screened with the conditions established for the racemic cyclizations, including typical chiral ligands such as bisoxazolines, as well as less common frameworks for catalysis such as brucine (not shown, see Supporting Information). As we observed during the development of our oxidative kinetic resolution chemistry, ${ }^{15 \mathrm{a}}$ the natural product ( $36 \mathrm{~h}$ )-sparteine was by far the most successful at inducing asymmetry in the cyclization. Treatment of 1 with $\operatorname{Pd}(\mathrm{TFA})_{2}$ in the presence of (-)-sparteine, MS3 $\AA$ and $\mathrm{O}_{2}$ in toluene led to a $72 \%$ conversion to $76 \%$ enantioenriched dihydrobenzofuran (+)-2 after $36 \mathrm{~h}$ (eq. 1). ${ }^{26}$

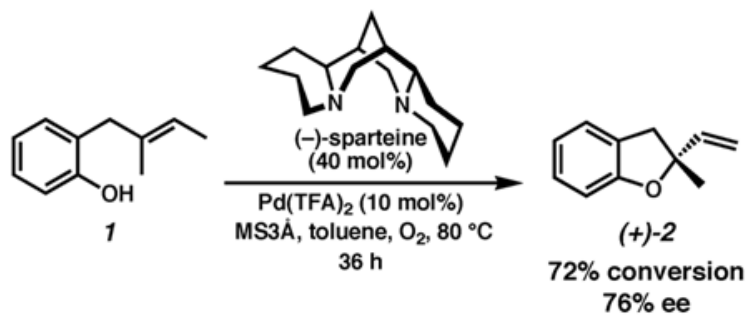

$J$ Am Chem Soc. Author manuscript; available in PMC 2008 November 21. 


\section{Optimization of the asymmetric reaction - screen of palladium sources}

With (-)-sparteine as the most enantioselective candidate to emerge from the chiral ligand screen, we set out to increase selectivity through an optimization of $\mathrm{Pd}(\mathrm{II})$ source and basic additive. This seemed essential in light of what we had observed during the development of the racemic reaction (cf. Table 1), as well as with the kinetic resolution chemistry. ${ }^{15 a, 27} \mathrm{Pd}$ (II) halide sources provided product in some cases, but with degradation of enantiomeric excess (Table 6, entries $1-2,4-5) . \mathrm{Pd}(\mathrm{OAc})_{2}$ is more effective at inducing asymmetry, but at the expense of conversion (entry 6). The extent of asymmetric induction varied surprisingly in the presence of different $\mathrm{Pd}(\mathrm{II})$ sources. For example, $\mathrm{Pd}(\mathrm{COD}) \mathrm{Cl}_{2}$ results in only $10 \%$ ee (entry 2 ), whereas $\mathrm{Pd}(\mathrm{TFA})_{2}$ provides $76 \%$ ee (entry 7$)$. It is remarkable that this change has such a large effect on enantioselectivity. ${ }^{28} \mathrm{Pd}(\mathrm{TFA})_{2}$ remained the optimal catalyst, and it was found that by using the complex of $\operatorname{Pd}(\mathrm{TFA})_{2}$ and (-)-sparteine directly rather than generating it in situ led to slightly improved and more reliable results (entry 8). Generally, more electrondeficient Pd sources were more selective in the cyclization. However, switching the anion from trifluoroacetate to triflate resulted in degradation of the catalyst (formation of Pd black). In addition to palladium source, a basic additive affects reaction rate and selectivity. Best results occur with $\mathrm{Ca}(\mathrm{OH})_{2}$, the presynthesized (sp)Pd(TFA $)_{2}$ complex, and 1 equiv of (-)-sparteine (entry 11).

\section{Asymmetric oxidative cyclization of phenol substrates}

Under the optimized conditions, phenol $\mathbf{1}$ was cyclized to provide dihydrobenzofuran (+)-2 in $81 \%$ ee and $87 \%$ isolated yield (Table 7, entry 1 ). ${ }^{29}$ Application of these conditions to other substrates that reacted successfully under the racemic conditions proved difficult. ${ }^{30} p$ Methoxyphenol $\mathbf{7}$ is transformed with high selectivity to give (+)-8 in $90 \%$ ee and $57 \%$ yield (entry 2). $t$-Butylphenol $\mathbf{5}$ and $p$-methylphenol $\mathbf{3}$ do not react quickly but are obtained with good levels of enantiomeric excess (entries 3 and 4). $p$-Acylphenol 9 cyclizes, but with low \% ee, perhaps indicative of a change in mechanism for this less electron-rich substrate.

Unfortunately, the highly enantioentriched $p$-methoxy dihydrobenzofuran (+)-8 is produced with a dimeric aryl ether byproduct (50, Table 8$)$. This byproduct could form via palladation ortho to the phenol, followed by coupling to another molecule of substrate. The addition of various acids suppressed the formation of the byproduct, perhaps by decomposing the postulated palladium aryl species, but also depressed the enantioselectivity of the cyclization (entry 3).

While the asymmetric oxidative cyclization conditions that we have developed are not yet general, we have established that it is possible to adapt a direct dioxygen-coupled racemic reaction to aerobic asymmetric catalysis, which had not been achieved previously for this class of reaction. In conjunction with our work on the oxidative kinetic resolution of secondary alcohols, the asymmetric cyclization chemistry makes significant headway into the realm of enantioselective oxidase-type chemistry.

\section{Mechanistic investigations}

Deuterium-labeling studies of primary alcohol substrates in the presence of a monodentate ligand-We hypothesized that the sluggishness of the asymmetric cyclization could be attributed to the difference in ligand denticity between pyridine and (-)-sparteine. In fact, in our screen of nitrogen-containing ligands (Table 2), the decreased reactivity of all the bidentate ligands confirmed that (-)-sparteine was not uniquely deactivating. We thus wished to gain an understanding of the mechanism of the cyclization, and whether a change from a mono- to a bidentate ligand would involve a change in mechanism. One commonly proposed mechanism for Pd(II)-catalyzed cyclizations involves activation of the olefin by $\mathrm{Pd}(\mathrm{II})$ 
followed by anti nucleophilic attack, i.e, anti oxypalladation; indeed, this was our original hypothesis. ${ }^{18,31}$ The resulting Pd-alkyl intermediate would then undergo $\beta$-hydrogen elimination. Such a mechanism is reminiscent of that proposed by Bäckvall, Stille and Kurosawa for the Wacker oxidation of ethylene to acetaldehyde. ${ }^{32}$ A second possible mechanism is supported by recent reports from Hayashi and Wolfe that find certain heteroatom/ olefin cyclizations catalyzed by Pd(II) occur with syn oxypalladation. ${ }^{33}$ Wolfe further suggests that this involves an olefin insertion into a $\mathrm{Pd}(\mathrm{II})$-heteroatom bond. $34,35,36$ This pathway is analogous to the alternative mechanism for the Wacker oxidation proposed by Henry and others that involves syn oxypalladation. ${ }^{37} \mathrm{~A}$ third mechanism entails allylic $\mathrm{C}-\mathrm{H}$ activation by $\mathrm{Pd}$ (II) to form an intermediate $\pi$-allyl species that would then undergo reductive elimination with the heteroatom nucleophile. $9,38,39$

We set out to differentiate these mechanisms by synthesizing stereospecifically deuteriumlabeled substrates, and observing the products of the cyclization in the presence of a monoand bidentate ligand. Deuterium-labeled alcohols trans-3- $\boldsymbol{d}-\mathbf{5 3}$ and $\boldsymbol{c i s}-\mathbf{3 - \boldsymbol { d } - \mathbf { 5 3 }}$ were designed such that oxidative cyclization would result in retention or elimination of the label. Recently, during the course of this work, Hayashi and coworkers reported a similar study for the oxidative cyclization of olefin-appended phenols by $\mathrm{Pd}(\mathrm{II})$; in those examples syn oxypalladation occurs exclusively except in the presence of additional chloride ion. ${ }^{33 \mathrm{a}} \mathrm{We}$ chose to focus on primary alcohols because of the interesting dichotomy between oxidative cyclization and alcohol oxidation and because a study of this type had not yet been carried out for this substrate class.
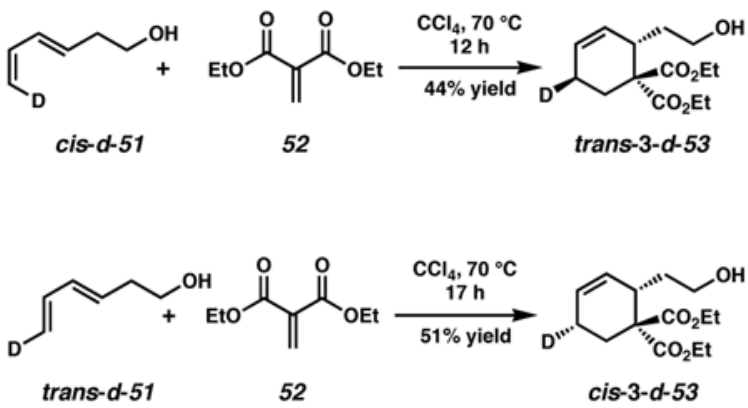

Stereospecific deuterium incorporation into primary alcohol substrates could be effected with the Diels-Alder reaction shown in eqs. 2 and 3 that completed the relatively straightforward synthesis of trans- and cis-3-d-53. ${ }^{40}$ We assumed the constraints that a cis 6-5 fused ring system would form, and that $\beta$-hydrogen elimination only occur when the Pd atom and eliminated $\mathrm{H}$ or $\mathrm{D}$ atom are syn to each other. ${ }^{41}$ The presence or absence of a deuterium label in the product would then differentiate mechanistic pathways. Although a $\pi$-allyl mechanism could be difficult to unambiguously rule out with our test substrate, we hoped to at least distinguish syn from anti oxypalladation. ${ }^{42}$

Treatment of trans-3-d-53 with 10 mol\% (pyridine) ${ }_{2} \mathrm{Pd}(\mathrm{TFA})_{2}, 20 \mathrm{~mol} \%$ pyridine, 2 equiv $\mathrm{Na}_{2} \mathrm{CO}_{3}, 1$ atm $\mathrm{O}_{2}$ and $500 \mathrm{mg} / \mathrm{mmol} \mathrm{MS} 3 \AA$ in toluene at $80^{\circ} \mathrm{C}$ for $3 \mathrm{~h}$ provided 3- $\boldsymbol{d}-\mathbf{5 4}$ along with olefin isomer 3- $\boldsymbol{d}-\mathbf{5 5}$ in a $4: 1$ ratio and $95 \%$ overall yield (Scheme 1). Likewise, reaction

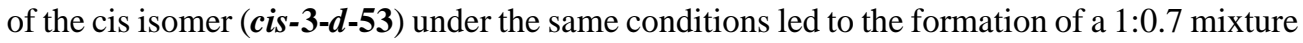
of undeuterated 54 and $\boldsymbol{c i s}-\mathbf{2}-\boldsymbol{d}-\mathbf{5 5}$ in nearly quantitative yield. Reaction of $\boldsymbol{c i s}-\mathbf{3 - d}-\mathbf{- 5 3}$ in the absence of $\mathrm{Na}_{2} \mathrm{CO}_{3}$ leads to a nearly identical result. ${ }^{43}$ The stereochemistry of $\boldsymbol{c i s}-\mathbf{- 2}-\boldsymbol{d}-\mathbf{5 5}$ was confirmed by ${ }^{1} \mathrm{H}$ NMR homodecoupling and NOE experiments. ${ }^{40}$ Reexposure of the product mixture (54 and $\boldsymbol{c i s}-\mathbf{2}-\boldsymbol{d} \mathbf{- 5 5})$ to the same reaction conditions and an additional $10 \mathrm{~mol} \%$ starting material (cis-3-d-53) for $4 \mathrm{~h}$ resulted in an identical ratio of products in $90 \%$ isolated yield. Comparison of the ${ }^{1} \mathrm{H}$ and ${ }^{2} \mathrm{H}$ NMR spectra of the products of the above reactions with those 
formed from undeuterated cyclohexene $\mathbf{5 3}$ confirmed the presence or absence of a deuterium label. ${ }^{40}$

The mechanistic origin of the products, illustrated for the cis diastereomer (cis-3-d-53), is shown in Scheme 2. For comparison, all three possible pathways are shown. Path A involves anti nucleophilic attack of the Pd-coordinated olefin by the pendant alcohol or alkoxide. Subsequent $\beta$-hydrogen elimination would lead to the deuterium labeled product 3- $d-\mathbf{5 4}$, but this product is not observed (vide supra, Scheme 1). In Path B, oxypalladation entails allylic $\mathrm{C}-\mathrm{H}(\mathrm{D})$ activation and subsequent reductive elimination to $\mathrm{Pd}(0)$ upon formation of the $\mathrm{C}-\mathrm{O}$ bond. The stereochemistry of the reductive elimination would likely be anti. ${ }^{44}$ Further, unless selective $\mathrm{C}-\mathrm{D}$ activation occurs, a mixture of labeled and unlabeled products would be expected; instead a single product is observed. In Path $\mathrm{C}$, a Pd-alkoxide undergoes syn oxypalladation followed by syn $\beta$-deuterium elimination to provide the observed major product, 54. Reinsertion of the Pd-D intermediate to the product olefin accounts for formation of the observed minor product, $\boldsymbol{c i s} \mathbf{- 2}-\boldsymbol{d} \mathbf{- 5 5} .^{45}$ The fact that an identical product mixture is obtained upon reexposure of the products to the reaction conditions supports the occurrence of reinsertion before dissociation of the product olefin from the Pd-D fragment. ${ }^{46}$ Finally, because the $\mathrm{Pd}^{0}$ intermediate in Path $\mathrm{B}$ cannot easily account for the formation of olefin isomer cis-2-d-55, we favor syn oxypalladation Path C.

The remaining steps of the catalytic cycle involve reprocessing of Pd(II) by molecular oxygen. On the basis of earlier work by Murahashi and Takehira, $3 \mathrm{~g}, 47$ Uemura has proposed that this occurs by insertion of $\mathrm{O}_{2}$ directly into the $\left[\mathrm{Pd}^{\mathrm{II}}\right]-\mathrm{H}$ to form a Pd-hydroperoxide intermediate. 17a Stahl has elaborated the details of a mechanism for aerobic oxidation catalysis by $\mathrm{Pd}(\mathrm{II})$ that entails reductive elimination of $\mathrm{HX}$ from $\left[\mathrm{Pd}^{\mathrm{II}}\right]-\mathrm{H}$ to form $\mathrm{Pd}(0)$ which is then oxidized by $\mathrm{O}_{2}$ in the formation of a Pd-peroxo intermediate. ${ }^{48,49}$ In any case, these steps and those outlined in Scheme 2 proceed through $\mathrm{Pd}(\mathrm{II})$ and $\mathrm{Pd}(0)$ intermediates; however, we cannot definitively discount a process involving $\mathrm{Pd}(\mathrm{IV}) .50$

We strove to further discount the $\pi$-allyl mechanism (Path B, Scheme 2 ) by comparing the reactivity of two phenol substrates. As shown in Scheme 3, a phenol with a disubstituted pendant olefin (23) cyclizes in good yield to provide dihydrobenzofuran $\mathbf{2 4}$. The most likely $\pi$-allyl species to form from $\mathbf{2 3}$ would involve activation of a benzylic proton (63), but intramolecular nucleophilic attack of this intermediate $(\mathbf{6 3})$ would not lead to 24 . The $\pi$-allyl intermediate that could lead to cyclization (64) could be expected to arise from terminal olefin $\mathbf{6 2}$ as well (Scheme 3); both starting materials would lead to the same cyclized product (24). Instead, treatment of $\mathbf{6 2}$ with our standard racemic conditions leads to a complex mixture after several hours and less than $5 \%$ of $\mathbf{2 4}$. It may be that allylic or benzylic $\mathrm{C}-\mathrm{H}$ activation does occur, but is not productive for cyclization.

To explore whether the large effect of Pd(II) source on reactivity originated from a change in mechanism, the cyclization of $\boldsymbol{c i s} \mathbf{- 3 -} \boldsymbol{d} \mathbf{- 5 3}$ was carried out under the same reaction conditions but in the presence of (pyridine) ${ }_{2} \mathrm{PdCl}_{2}$ (eq. 4). ${ }^{51}$ The initial cyclization product (55) was identical to that obtained under the conditions employing (pyridine) ${ }_{2} \mathrm{Pd}(\mathrm{TFA})_{2}$; however, the olefin isomer cis-2-d-55 was now the major product. The cyclic ethers were obtained along with aldehyde $\boldsymbol{c i s}-\mathbf{3 - \boldsymbol { d } - \mathbf { 6 5 }}$ in $\mathbf{7 4 \%}$ overall yield after $20 \mathrm{~h}$. The formation of ether $\mathbf{5 5}$ and ether $\boldsymbol{c i s - 2 - \boldsymbol { d } - 5 5}$ implies that syn oxypalladation still occurs, contrary to what Hayashi observed for a similar phenol substrate, for which anti oxypalladation dominates upon the addition of chloride ion. ${ }^{33 \mathrm{a}}$ The formation of aldehyde $\boldsymbol{c i s}-\mathbf{3 - \boldsymbol { d }} \boldsymbol{d} \mathbf{- 6 5}$ likely occurs from a common alkoxide intermediate, and highlights the effect that subtle changes in reaction conditions can have on the mode of oxidation. 


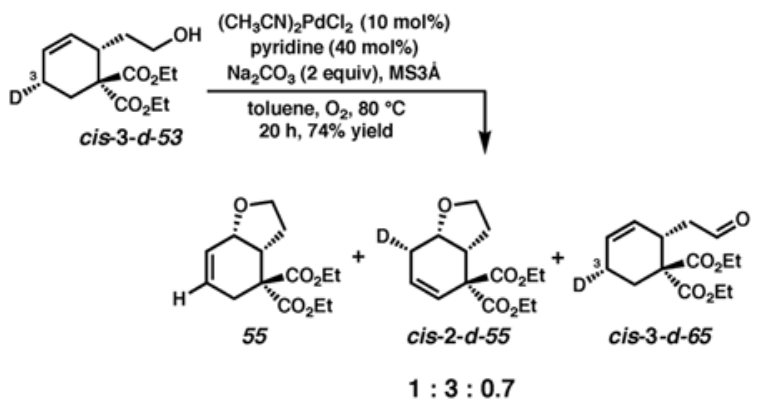

\section{Deuterium-labeling studies of primary alcohol substrates in the presence of a} bidentate ligand-The deuterium labeled alcohol substrates trans-3-d-53 and $\boldsymbol{c i s}-\mathbf{3 - d} \boldsymbol{d - 5 3}$ were then cyclized under conditions that employed dipyridyl as a bidentate ligand. Treatment of both trans-3-d-53 and $\boldsymbol{c i s}$-3- $\boldsymbol{d}-\mathbf{5 3}$ with $10 \mathrm{~mol} \%$ (dipyridyl)Pd(TFA) ${ }_{2}, \mathrm{Na}_{2} \mathrm{CO}_{3}$ (2 equiv), 1 atm $\mathrm{O}_{2}, 500 \mathrm{mg} / \mathrm{mmol} \mathrm{MS} 3 \AA$ in toluene at $80^{\circ} \mathrm{C}$ led to the formation of the same major products (3-d-54 and 54, respectively) observed with the conditions that use pyridine (Scheme 4). None of the olefin isomer was observed; instead a small amount of aldehyde (trans-3-d-65 and cis-3$\boldsymbol{d}$-65) was formed for both starting material diastereomers. ${ }^{52}$ Both diastereomers were slower to cyclize in the presence of (dipyridyl) $\mathrm{Pd}(\mathrm{TFA})_{2}$ than in the presence of (pyridine) ${ }_{2} \mathrm{Pd}$ $(\mathrm{TFA})_{2}$. The reaction of trans-3- $\mathbf{d - 5 3}$ under the asymmetric conditions using $(-)$-sparteine led only to oxidation to the aldehyde. The major product distribution from cyclization in the presence of both a mono- and bidentate ligand is the same. Presumably the aldehyde forms via $\beta$-hydrogen elimination from a common alkoxide intermediate before oxypalladation can occur.

On the basis of the results outlined above, we propose that at least for the alcohol substrates, reaction under mono- or bidentate ligated conditions occurs by a similar pathway. The difference in reaction rate could arise from the degree to which each ligand can stabilize intermediates under otherwise identical reaction conditions. A neutral monodentate ligand like pyridine can dissociate when necessary to free a coordination site for the substrate while maintaining charge-neutral intermediates (67-69, Scheme 5, A). When dipyridyl is used, neutral ligand dissociation may be more difficult due to chelation, and instead an anionic ligand must dissociate, resulting in charged intermediates ( $\mathbf{7 1}$ and $\mathbf{7 3}$, Scheme 5, B). Such intermediates may be higher in energy under the reaction conditions, which in turn results in decreased reactivity. ${ }^{53}$ (-)-Sparteine (cf. Scheme 4 ) not only leads to the same limitation, but also prevents cyclization, perhaps due to steric congestion at $\mathrm{Pd}$ that prevents formation of the $\mathrm{Pd}-\mathrm{O}-$ olefin chelate (71).

Although an extension of these mechanistic conclusions to the racemic and asymmetric phenol cyclizations may be tenuous, the same scenario would account for the slowness of the reactions catalyzed by $((-) \text {-sparteine)Pd(TFA })_{2}$ relative to (pyridine $)_{2} \mathrm{Pd}(\mathrm{TFA})_{2}$. Hayashi and coworkers' results also support this conclusion. Their system undergoes syn oxypalladation in the presence of a bidentate ligand with a dicationic Pd(II) catalyst in methanol using benzoquinone as the terminal oxidant. ${ }^{33 \mathrm{a}}$ The higher dielectric solvent and dicationic catalyst may facilitate the formation of the charged intermediates shown in Scheme 5B, whereas our toluene-based conditions slow their formation. Because most of the chiral ligands that are effective in inducing asymmetry are bidentate, the mechanistic implication of the results described above is that selectivity and good reactivity will be difficult to attain in the $\mathrm{Pd}(\mathrm{II}) /$ toluene/ $\mathrm{O}_{2}$ system. 
Deuterium-labeling studies of carboxylic acid substrates-Alcohols trans-3- $d-53$ and $\boldsymbol{c i s}$-3- $\boldsymbol{d}-\mathbf{5 3}$ were oxidized 40 to the corresponding carboxylic acid derivatives (trans-3$\boldsymbol{d}-\mathbf{- 7 4}$ and $\boldsymbol{c i s}$-3- $\boldsymbol{d}$-74) and subjected to the cyclization conditions that employ pyridine (Scheme 6). Both were slow to cyclize and formation of Pd-black was observed; nevertheless, some product was obtained and analyzed by ${ }^{1} \mathrm{H}$ and ${ }^{2} \mathrm{H}$ NMR. In contrast to the alcohol substrates, the formation of unlabeled lactone 75 from trans-3- $d-74$ and labeled lactone 3-d-75 from cis-3$\boldsymbol{d - 7 4}$ indicates that cyclization of the acid proceeds through anti oxypalladation. The olefin isomer arising from reinsertion was not observed. Cyclization of trans-3-d-74 in the absence of $\mathrm{Na}_{2} \mathrm{CO}_{3}$ resulted in greatly diminished yield (4\% yield after $24 \mathrm{~h}$ ) of the same product (75) but slower formation of Pd-black, which indicates that the inorganic base does not affect the stereochemistry of oxypalladation, but may play a role in catalyst decomposition.

Although the reasons for the change in product distribution at this point remain unclear, geometrical constraints, $\mathrm{pK}_{\mathrm{a}}$ differences, or differences in nucleophilicity between an acid and an alcohol are all possibilities. The additional unsaturation in the forming lactone could make geometrically unfavorable the $\mathrm{Pd}-\mathrm{O}-$ olefin chelate that would precede syn oxypalladation. Whatever the case, these results confirm the versatility and undiscriminating reactivity of Pd (II) catalysts in oxidation reactions. As demonstrated by these results and the accumulating evidence from several groups, generalizations about reactivity and mechanism that span different substrates and different reaction conditions are difficult to make for palladium catalyzed oxidation reactions. $9,32,33,37,38,50$

\section{SUMMARY AND CONCLUSION}

In summary, we have demonstrated that oxidase-type cyclizations of several different nucleophiles onto pendant olefins can be achieved in excellent yields under simple conditions. Reactivity is highly dependent on Pd(II) source, basic additive, and ligand. Several different types of cyclic systems are attainable, including aryl and alkyl bicycles, as well as fused and spirocyclic motifs. These cyclizations are part of an ongoing effort to develop enantioselective oxidase-type reactions using $\mathrm{Pd}(\mathrm{II})$ catalysis and molecular oxygen. To this end, the racemic conditions we developed were suitable for extension to an enantioselective cyclization that uses the chiral ligand (-)-sparteine. While the asymmetric oxidative cyclization conditions that we have developed are not yet general, we have established that it is possible to adapt a direct dioxygen-coupled racemic reaction to aerobic asymmetric catalysis, which had not before been achieved for this class of reaction. In conjunction with our work on the oxidative kinetic resolution of secondary alcohols, the asymmetric cyclization chemistry is a significant stride into the arena of enantioselective oxidase-type chemistry.

Stereospecifically deuterated primary alcohol substrates were used to probe the stereochemistry of oxypalladation and to gain insight into the mechanism of cyclization. Contrary to the common mechanistic proposal for reactions of this type (i.e., "Wacker cyclization" or anti oxypalladation), reaction of the primary alcohol substrates appears to occur via syn oxypalladation. This is in agreement with more recent reports from Hayashi and Wolfe on related systems. Neither the presence of chloride anion, nor the use of a bidentate instead of a monodentate ligand changes the stereochemistry of oxypalladation. The implications for the asymmetric reaction are that bidentate ligands may destabilize the intermediates necessary for a syn oxypalladation pathway; thus reactivity is decreased relative to the conditions employing a monodentate ligand. On the other hand, similarly deuterated carboxylic acid substrates react in the opposite sense, i.e., via anti oxypalladation.

As contemporary work in this rapidly developing, recently reborn field continues to demonstrate, oxidase-type catalysis by $\mathrm{Pd}(\mathrm{II})$ is highly versatile and adaptable to a variety of applications. ${ }^{54}$ Our studies reported herein emphasize the subtleties of reactivity and 
mechanism in this field. Further development of dehydrogenation reactions using Pd(II) and molecular oxygen, racemic and asymmetric, is ongoing.

\section{Supplementary Material}

Refer to Web version on PubMed Central for supplementary material.

\section{Acknowledgements}

The authors wish to thank the NIH-NIGMS (R01 GM65961-01), Bristol-Myers Squibb Company and the American Chemical Society (graduate fellowship to R.M.T.), the University of California TRDRP (postdoctoral fellowship to Y.K.R.), the Dreyfus Foundation, Merck Research Laboratories, Research Corporation, Abbott Laboratories, Pfizer, Amgen, GlaxoSmithKline, Lilly, and Johnson and Johnson for generous financial support. Drs. Eric Ferreira, Jonathan Owen, and Andrew Waltman are acknowledged for helpful discussions.

\section{REFERENCES SECTION}

1. (a)JohnsonRASharplessKBOjimaICatalytic Asymmetric SynthesisWiley \& Sons, IncNew York2000231280(b)KatsukiTOjimaICatalytic Asymmetric SynthesisWiley \& Sons, IncNew York2000287325(c)JacobsenENJaobsenENPfaltzAYamamotoHComprehensive Asymmetric 21 Catalysis2SpringerBerlin1999607618For a recent review of advances in transition metal catalyzed oxidation, see: (d) Punniyamurthy T, Velusamy S, Iqbal J. Chem Rev 2005;105:2329-2364. [PubMed: 15941216]

2. Tsuji, J. Palladium Reagents and Catalysis. John Wiley \& Sons, Ltd; Chichester, UK; Hoboken, NJ: 2004. Negishi, E., editor. Handbook of Organopalladium Chemistry for Organic Synthesis. Wiley \& Sons, Inc; New York: 2002. (c) Tietze LF, Ila H, Bell HP. Chem Rev 2004;104:3453-3516. [PubMed: 15250747]

3. For reviews, see: (a) Stoltz BM. Chem Lett 2004;33:362-367. (b) Stahl SS. Angew Chem, Int Ed 2004;43:3400-3420. (c) Sigman MS, Schultz MJ. Org Biomol Chem 2004;2:2551-2554. [PubMed: 15351815]For a recent review of Pd-catalyzed alcohol oxidation, see: (d) Muzart J. Tetraherdon 2003;59:5789-5816. (e) Trost BM. Acc Chem Res 1990;23:34-42. (f) Hedgedus LS. Tetrahedron 1984;40:2415-2434. (g) Hosokawa T, Murahashi SI. Acc Chem Res 1990;23:49-54. (h) Semmelhack MF, Kim C, Zhang N, Bodurow C, Sanner M, Dobler W, Meier M. Pure Appl Chem 1990;23:20352040.(i)TsujiJPalladium Reagents and CatalystsJohn Wiley \& Sons, LtdChichester, UK1995125527 (j) Zeni G, Larock RC. Chem Rev 2004;104:2285-2309. [PubMed: 15137792] (k) Wolfe JP, Thomas JS. Curr Org Chem 2005;9:625-655.

4. Blackburn TF, Schwartz J. J Chem Soc, Chem Commun 1977:157-158.

5. For examples of phenol cyclizations, see: (a) Larock RC, Wei L, Hightower T. Synlett 1998:522524.For examples of alcohol cyclizations, see: (b) Rönn M, Bäckvall J-E, Andersson PG. Tetrahedron Lett 1995;36:7749-7752.For examples of acid cyclizations, see: (c) Larock RC, Hightower TR. J Org Chem 1993;58:5298-5300.For examples of tosylamide cyclizations, see: (d) Larock RC, Hightower TR, Hasvold LA, Peterson KP. J Org Chem 1996;61:3584-3585. [PubMed: 11667199] and references thereinFor examples of primary and secondary alcohol oxidation to aldehydes and ketones, see: (e) Peterson KP, Larock RC. J Org Chem 1998;63:3185-3189.

6. For examples of racemic systems that employ the copper/O $\mathrm{O}_{2}$ system, see: Phenol cyclizations: (a) Hosokawan T, Ohkata H, Moritani I. Bull Chem Soc Japan 1975;48:1533-1536.Alcohol cyclizations: (b) Hosokawa T, Hirata M, Murahashi S-I, Sonoda A. Tetrahedron Lett 1976;21:1821-1824.

7. For examples of racemic systems that employ benzoquinone, see Aniline cyclizations: (a) Hegedus LS, Allen GF, Bozell JJ, Waterman EL. J Am Chem Soc 1978;100:5800-5807.For oxidative carboncarbon bond forming aryl/olefin cyclizations: (b) Zhang H, Ferreira EM, Stoltz BM. Angew Chem, Int Ed 2004;43:6144-6148.

8. In contrast, reactions that are solely aerobic produce only $\mathrm{H}_{2} \mathrm{O}$ or $\mathrm{H}_{2} \mathrm{O}_{2}$ as byproducts.

9. (a) Thorarensen A, Palmgren A, Itami K, Bäckvall JE. Tetrahedron Lett 1997;38:8541-8544. (b) Itami K, Palmgren A, Thorarensen A, Bäckvall JE. J Org Chem 1998;63:6466-6471. (c) Cotton HK, Verboom RC, Johansson L, Plietker BJ, Bäckvall JE. Organometallics 2002;21:3367-3375. 
10. Chen MS, Prabagaran N, Labenz NA, White MC. J Am Chem Soc 2005;102:6970-6971. [PubMed: 15884938]

11. (a) Hosokawa T, Uno T, Inui S, Murahashi SI. J Am Chem Soc 1981;103:2318-2323. (b) Hosokawa T, Okuda C, Murahashi SI. J Org Chem 1985;50:1282-1287.

12. (a) Uozumi Y, Kato K, Hayashi T. J Am Chem Soc 1997;119:5063-5064. (b) Uozumi Y, Kato K, Hayashi T. J Org Chem 1998;63:5071-5075. (c) Uozumi Y, Kyota H, Ogasawara M, Hayashi T. J Org Chem 1999;64:1620-1625. [PubMed: 11674227]

13. Arai MA, Kuraishi M, Arai T, Sasai H. J Am Chem Soc 2001;123:2907-2908. [PubMed: 11456988]

14. For examples of non-oxidative Pd(II)-mediated enantioselective catalysis, see: (a) Fuiji A, Hagiwara E, Sodeoka M. J Am Chem Soc 1999;121:5450-5458. (b) El-Qisairi A, Hamed O, Henry PM. J Org Chem 1998;63:2790-2791. (c) Zhang Q, Lu X. J Am Chem Soc 2000;122:7604-7605. (d) Overman LE, Remarchuk TP. J Am Chem Soc 2002;124:12-13. [PubMed: 11772049]

15. (a) Ferreira EM, Stoltz BM. J Am Chem Soc 2001;123:7725-7726. [PubMed: 11481006] (b) Bagdanoff JT, Ferreira EM, Stoltz BM. Org Lett 2003;5:835-837. [PubMed: 12633084] (c) Caspi DD, Ebner DC, Bagdanoff JT, Stoltz BM. Adv Synth Catal 2004;346:185-189.For conditions employing chloroform and air, see: (d) Bagdanoff JT, Stoltz BM. Angew Chem, Int Ed 2004;43:353357. (e) Trend RM, Stoltz BM. J Am Chem Soc 2004;126:4482-4483. [PubMed: 15070342]

16. For a similar system, see: (a) Jensen DR, Pugsley JS, Sigman MS. J Am Chem Soc 2001;123:74757476. [PubMed: 11472200] (b) Mueller JA, Jensen DR, Sigman MS. J Am Chem Soc 2002;124:8202-8203. [PubMed: 12105896] (c) Jensen DR, Sigman MS. Org Lett 2003;5:63-65. [PubMed: 12509891] (d) Mandal SK, Jensen DR, Pugsley JS, Sigman MS. J Org Chem 2003;68:4600-4603. [PubMed: 12762783] (e) Mueller JA, Sigman MS. J Am Chem Soc 2003;125:7005-7013. [PubMed: 12783555] (f) Mandal SK, Sigman MS. J Org Chem 2003;68:75357537. [PubMed: 12968915]

17. (a) Nishimura T, Onoue T, Ohe K, Uermura S. J Org Chem 1999;64:6750-6755. [PubMed: 11674682] Uemura has used similar conditions for the ring cleavage of tert-cyclobutanols, see: (b) Nishimura T, Ohe K, Uemura S. J Am Chem Soc 1999;121:2645-2646.Related heterogeneous conditions that use a hydrotalcite solid support have been developed: (c) Kakiuchi N, Maeda Y, Nishimura T, Uemura S. J Org Chem 2001;66:6620-6625. [PubMed: 11578212]

18. Trend RM, Ramtohul YK, Ferreira EM, Stoltz BM. Angew Chem, Int Ed 2003;42:2892-2895.

19. Ferreira EM, Stoltz BM. J Am Chem Soc 2003;125:9578-9579. [PubMed: 12904010]

20. (a) Anton DR, Crabtree RH. Organometallics 1983;2:855-859. (b) Foley P, DiCosimo R, Whitesides GM. J Am Chem Soc 1980;102:6713-6725.

21. For an example of a Pd-catalyzed phenol/olefin cyclization using an N-heterocyclic carbene ligand, see: Muñiz K. Adv Synth Catal 2004;346:1425-1428.

22. For a recent review of Pd-catalyzed reactions of alcohols to form ether linkages, see: Muzart J. Tetrahedron 2005;61:5955-6008.

23. Semmelhack MF, Kin CR, Dobler W, Meier M. Tetrahedron Lett 1989;30:4925-4928.

24. Åkermark B, Larsson EM, Oslob JD. J Org Chem 1994;59:5729-5733.

25. A similar cyclization of sulfonamides was recently reported, see: Fix SR, Brice JL, Stahl SS. Angew Chem, Int Ed 2002;41:164-166.

26. $10 \mathrm{~mol} \% \mathrm{Pd}(\mathrm{TFA})_{2}, 40 \mathrm{~mol} \%$ ligand, $500 \mathrm{mg} / \mathrm{mmol} \mathrm{MS} 3 \AA$, 0.41 equiv tridecane internal GC standard, Conversion and enantiomeric excess were determined by GC. 1 atm $\mathrm{O}_{2}$, toluene $(0.1 \mathrm{M})$, $80{ }^{\circ} \mathrm{C}$.

27. Attempted cyclization under the chloroform-based rate-enhanced conditions for oxidative kinetic resolution ((sp) $\mathrm{PdCl}_{2}(5 \mathrm{~mol} \%),(-)$-sparteine ( $\left.7 \mathrm{~mol} \%\right), \mathrm{Cs}_{2} \mathrm{CO}_{3}\left(0.4\right.$ equiv), $\mathrm{CHCl}_{3}(0.1 \mathrm{M}), \mathrm{O}_{2}(1$ atm, balloon), $25{ }^{\circ} \mathrm{C}$ ) resulted in no reaction.

28. A similar, albeit less dramatic counterion effect was observed in the oxidative kinetic resolution of secondary alcohols; see Ref. 15a and Nielsen RJ, Keith JM, Stoltz BM, Goddard WA III. J Am Chem Soc 2004;126:7967-7974. [PubMed: 15212546]

29. The absolute stereochemistry was determined by comparison of the optical rotation with that reported for (-)-2, by Uozumi and Hayashi, Ref. 12c (see Supporting Information for rotation data). We report the absolute stereochemistry of (+)-8, (-)-6, (+)-4 and (-)-10 by analogy to this substrate. 
30. Tetrasubstituted olefin-containing phenol 21, which is Hayashi's most selectively cyclized substrate, $12 \mathrm{a}$ fails to cyclize under our optimized conditions.

31. (a) Ref. $3 \mathrm{~g}$ and references therein. ColemanJPHegedusLSPrinciples and Applications of Organometallic ChemistryUniversity Science BooksMill Valley, CA1980401424

32. (a) Bäckvall JE, Åkermark B, Ljunggren SO. J Chem Soc, Chem Commun 1977:264-265. (b) Bäckvall JE, Åkermark B, Ljunggren SO. J Am Chem Soc 1979;101:2411-2416. (c) James DE, Hines LF, Stille JK. J Am Chem Soc 1976;98:1806-1809. (d) Stille JK, Divakaruni R. J Am Chem Soc 1978;100:1303-1304. (e) Majima T, Kurosawa H. J Chem Soc, Chem Commun 1977:610-611.

33. For systems containing oxygen nucleophiles, see: (a) Hayashi T, Yamasaki K, Mimura M, Uozumi Y. J Am Chem Soc 2004;126:3036-3037. [PubMed: 15012118] (b) Hay MB, Hardin AR, Wolfe JP. J Org Chem 2005;70:3099-3107. [PubMed: 15822970]For systems containing nitrogen nucleophiles, see: (c) Ney JE, Wolfe JP. Angew Chem, Int Ed 2004;43:3605-3608. (d) Ney JE, Wolfe JP. J Am Chem Soc 2005;127:8644-8657. [PubMed: 15954769]

34. Bäckvall and coworkers have characterized computationally the reactivity of nucleophiles toward cis migration, or olefin insertion, in $(\pi$-olefin)Pd(II) complexes and found that the HOMO-LUMO gap between the $\pi^{*}$ olefin orbital and a $\mathrm{Pd}-\mathrm{OH}$ nucleophile is too large for migration to be frontier controlled. Rather, the process is charge controlled, and likely does not occur through a concerted, 4-center transition state as in true olefin insertion reactions of $\mathrm{Pd}-\mathrm{CH}_{3}$ or $\mathrm{Pd}-\mathrm{H}$ nucleophiles. See: (a) Bäckvall JE, Björkman EE, Pettersson L, Siegbahn P. J Am Chem Soc 1984;106:4369-4373. (b) Bäckvall JE, Björkman EE, Pettersson L, Siegbahn P. J Am Chem Soc 1985;107:7265-7267.

35. For experimental evidence of insertion of tetrafluoroethylene into a Pt-O bond, see: Bryndza HE. Organometallics 1985;4:406-408.

36. For a recent example of olefin insertion into a rhodium amide, see: Zhao P, Krug C, Hartwig JF. J Am Chem Soc 2005;127:12066-12073. [PubMed: 16117547]

37. (a) Francis JW, Henry PM. Organometallics 1991;10:3498-3503. (b) Zaw K, Henry PM. Organometallics 1992;11:2832-2836. (c) Francis JW, Henry PM. Organometallics 1992;11:20082015. (d) Hamed O, Henry PM. Organometallics 1997;16:4903-4909. (e) Hamed O, Thompson C, Hernry PM. J Org Chem 1997;62:7082-7083. [PubMed: 11671803] (f) Hamed O, Henry PM, Thompson C. J Org Chem 1999;64:7745-7750. (g) ten, Brink G-J.; Arends, IWCW.; Papadogianakis, G.; Sheldon, RA. Appl Catal, A 2000;194-195:435-442. (h) Nelson DJ, Li R, Brammer C. J Am Chem Soc 2001;123:1564-1568. [PubMed: 11456754]

38. For evidence supporting this mechanism in intermolecular examples, see: (a) Grennberg H, Simon V, Bäckvall JE. J Chem Soc, Chem Commun 1994:265-266. (b) Grennberg H, Bäckvall JE. Chem Eur J 1998;4:1083-1089.

39. Trost has shown that $\mathrm{Pd}(\mathrm{TFA})_{2}$ will form $\pi$-allyl complexes by $\mathrm{C}-\mathrm{H}$ activation of olefins in acetone, see: Trost BM, Metzner PJ. J Am Chem Soc 1980;102:3572-3577.

40. See Supporting Information for details.

41. Examples of anti $\beta$-hydrogen elimination under various conditions have been reported, but involve aromatization or the formation of highly conjugated systems; see: (a) Toyota M, Ilangovan A, Okamoto R, Masaki T, Arakawa M, Ihara M. Org Lett 2002;4:4293-4296. [PubMed: 12443081] (b) Lautens M, Fang YQ. Org Lett 2003;5:3679-3682. [PubMed: 14507203] (c) Hughes CC, Trauner D. Angew Chem Int Ed 2002;41:1569-1572. (d) Buchwald SL, Hennessy EJ. J Am Chem Soc 2003;125:12084-12084. [PubMed: 14518981]

42. For a study that attempts to differentiate between oxypalladation and a $\pi$-allyl route for a Pd(II)catalyzed cyclization, see: Zanoni G, Porta A, Meriggi A, Franzini M, Vidari G. J Org Chem 2002;67:6064-6069. [PubMed: 12182643]

43. After $5.5 \mathrm{~h}, 89 \%$ yield of a 1:0.75 mixture of 54 and $c i s-2-d-55$ was obtained.

44. For a Pd(II)- $\pi$-allyl electrophile, a primary alcohol (or alkoxide) would fall into the class of "soft" nucleophiles, the conjugate acids of which as defined by Trost have a $\mathrm{pK}_{\mathrm{a}}<25$, see: Trost BM, Van Vranken DL. Chem Rev 1996;96:395-422. [PubMed: 11848758]

45. The difference in the product ratios formed from the trans and cis isomers could be accounted for by an isotope effect in the reinsertion step. Possibilities include: slower reinsertion for the [Pd]-H bound olefin than for the [Pd]-D bound olefin, faster dissociation for the [Pd]-H bound olefin, faster reductive elimination of $\mathrm{HX}$ before dissociation or reinsertion, or faster coordination and insertion 
of $\mathrm{O}_{2}$ into the [Pd]-H bond, if turnover of the catalyst occurs by that mechanism. At this time we cannot rule out any of or distinguish among these possibilities.

46. Because both [Pd]-D and [Pd]-H are formed, reinsertion after [Pd] dissociates from product 54 would lead to scrambling of the isotopic label.

47. Takehira K, Hayakawa T, Orita H. Chem Lett 1985:1835-1838.and references therein

48. (a) Stahl SS, Thorman JL, Nelson RC, Kozee MA. J Am Chem Soc 2001;123:7188-7189. [PubMed: 11459511]See also: (b) Steinhoff BA, Stahl SS. Org Lett 2002;4:4179-4181. [PubMed: 12423116]

49. Keith JM, Nielsen RJ, Oxgaard J, Goddard WA III. J Am Chem Soc 2005;127:13172-13179. [PubMed: 16173744]

50. In one scenario, oxidative activation of an allylic $\mathrm{C}-\mathrm{H}$ bond could lead to a $\mathrm{Pd}(\mathrm{IV})$-alkyl intermediate for the formation of a $\mathrm{Pd}(\mathrm{II}) \pi$-allyl species. Or, reductive elimination upon formation of the $\mathrm{C}-\mathrm{O}$ bond could lead to a Pd(II) intermediate. In another scenario, Pd(II) could undergo oxidative activation of an $\mathrm{O}-\mathrm{H}$ bond to form a $\mathrm{Pd}(\mathrm{IV})$-alkoxide, although this is unlikely in the presence of base. Although such pathways cannot be ruled out, the recently reported Pd oxidation reactions proposed to involve $\mathrm{Pd}(\mathrm{IV})$ also involve strong oxidizing agents such as $\mathrm{PhI}(\mathrm{OAc})_{2}$ and $\mathrm{I}_{2}$. For recent articles invoking Pd(IV) in Pd-catalyzed oxidative processes, see: (a) Dick AR, Hull KL, Sanford MS. J Am Chem Soc 2004;126:2300-2301. [PubMed: 14982422] (b) Dick AR, Kampf JW, Sanford MS. Organometallics 2005;24:482-485. (c) Alexanian EJ, Lee C, Sorensen EJ. J Am Chem Soc 2005;127:7690-7691. [PubMed: 15913354] (d) Yoneyama T, Crabtree RH. J Mol Catal A 1996;108:35-40.For a related Pd-catalyzed iodination system, see: (e) Giri R, Chen X, Yu JQ. Angew Chem, Int Ed 2005;44:2112-2115.

51. The catalyst was generated in situ by heating $\left(\mathrm{CH}_{3} \mathrm{CN}\right)_{2} \mathrm{PdCl}_{2}$ and all other reagents except the substrate for $15 \mathrm{~min}$ before addition of the substrate.

52. The identity of the aldehyde was confirmed by oxidation of the alcohol by another method, see Supporting Information.

53. We cannot rule out the possibility that the reaction with dipyridyl as ligand proceeds through similar intermediates with slow, partial dissociation of one of the dipyridyl nitrogen atoms. The reaction with (-)-sparteine as ligand is much less likely to undergo partial dissociation due to its structural rigidity.

54. (a) Sohn JH, Waizumi N, Zhong HM, Rawal VH. J Am Chem Soc 2005;127:7290-7291. [PubMed: 15898759] (b) Garg NK, Caspi DD, Stoltz BM. J Am Chem Soc 2005;127:5970-5978. [PubMed: 15839697] (c) Tietze LF, Sommer KM, Zinngrebe J, Stecker F. Angew Chem, Int Ed 2004;44:257259. 
<smiles>CCCC(C)O</smiles>

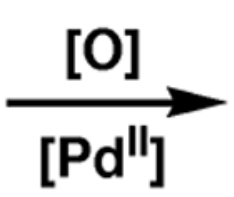<smiles>CCCC(C)=O</smiles><smiles>C=C[OH2+]</smiles><smiles>CCCCCc1cc(Br)ccc1C</smiles><smiles>CC=O</smiles><smiles>[X]C(=O)CCC1C=CCCC1</smiles>

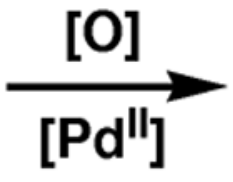<smiles>[Y]CCCC/C=C/C</smiles><smiles>[X]C1CCCCC1CCC(=O)O</smiles><smiles>[R]n1cc(CCC(C)=CC)c2ccccc21</smiles>

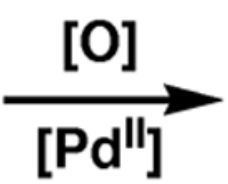<smiles>[R]n1c2c(c3ccccc31)CCC2(C)C=C</smiles>

[O] = Benzoquinone, $\mathrm{Cu} / \mathrm{O}_{2}, \mathrm{O}_{2} / \mathrm{DMSO}, \mathrm{O}_{2}$

Figure 1.

Prototypical $\mathrm{Pd}(\mathrm{II})$-catalyzed dehyrogenation reactions. 


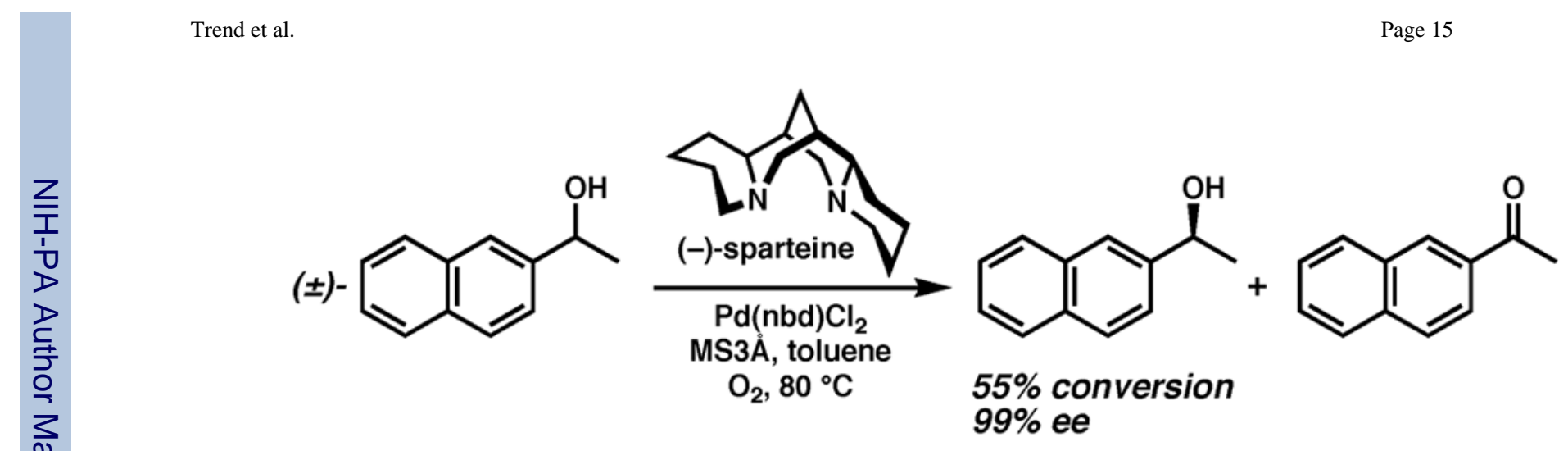

Figure 2.

An oxidase-type kinetic resolution of secondary alcohols. 


$$
\left(\begin{array}{cc} 
& \begin{array}{c}
\text { pyridine (30 mol\%) } \\
\mathrm{Na}_{2} \mathrm{CO}_{3} \text { (2 equiv), } \mathrm{MS} 3 \AA
\end{array} \\
\text { toluene, } \mathrm{O}_{2}, 80^{\circ} \mathrm{C}
\end{array}\right.
$$<smiles>[2H][C@H]1C=C[C@H](CCO)C(C(=O)OCC)(C(=O)OCC)C1</smiles>

trans-3- $d-53$
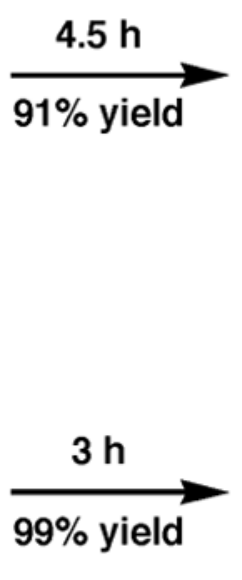

cis-3-d-53

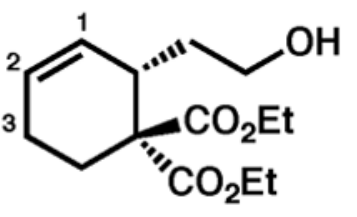

53

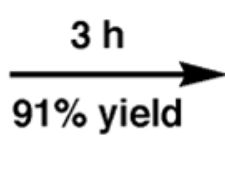<smiles>CCOC1(OCC)CC=C[C@H]2OCC[C@@H]21</smiles>

54<smiles>[2H]C1=C[C@@](C)(OCC)[C@H]2CCO[C@H]2C1</smiles>

3-d-55

$4: 1$<smiles>CCOC1(OCC)CC=C[C@H]2OCC[C@@H]21</smiles>

54<smiles>[2H][C@H]1C=C[C@@](COCC)(OCC)[C@H]2CCO[C@@H]12</smiles>

cis-2-d-55

$1: 0.7$<smiles>CCOC[C@@]12[C@@H]3CCO[C@H]3[C@@H]1C=CC2(OCC)OCC</smiles>

55

\section{$4: 1$}

Scheme 1.

Cyclization of deuterium-labeled primary alcohol substrates with pyridine as ligand. 


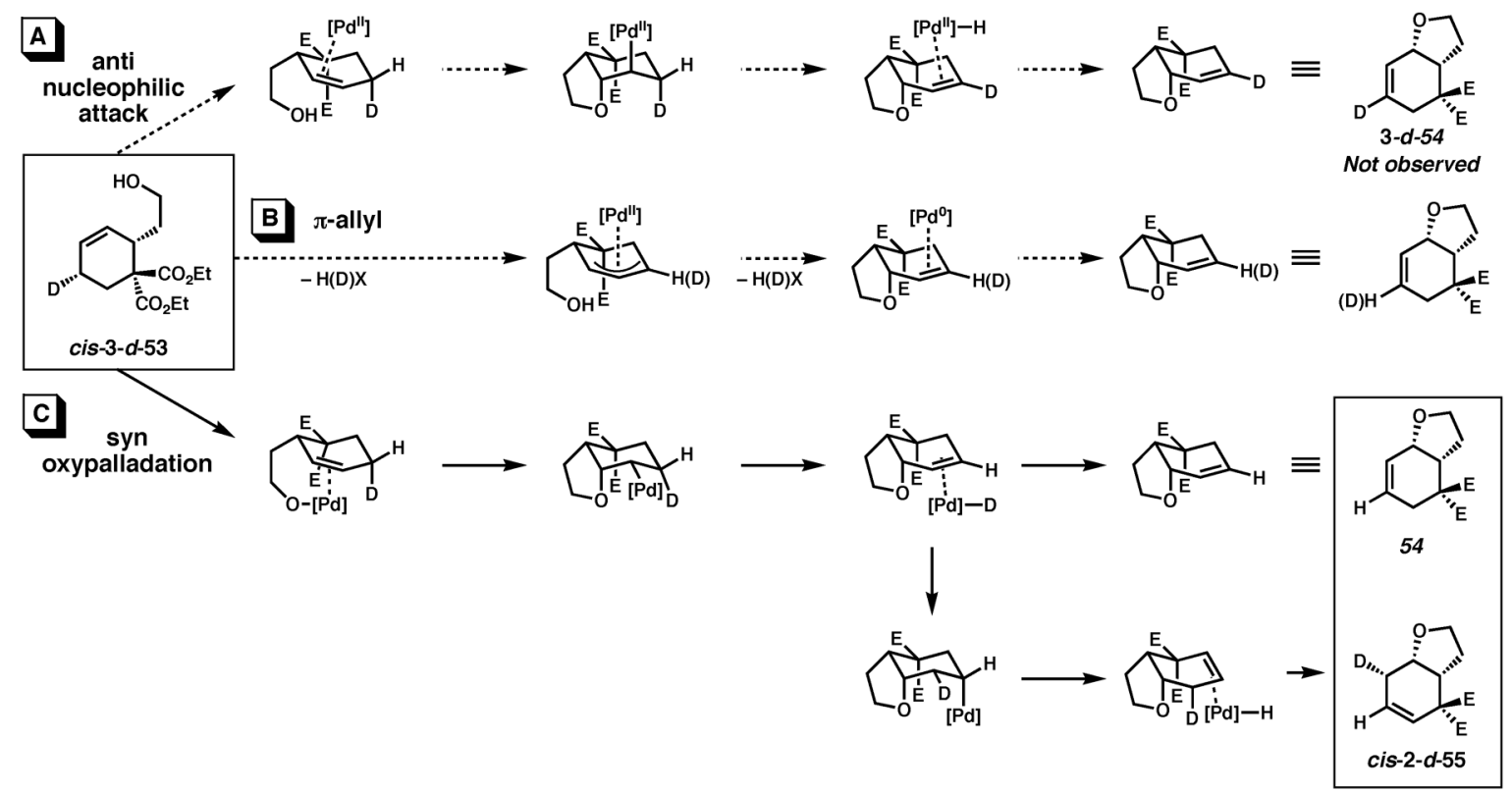

Scheme 2.

Three oxypalladation pathways. 


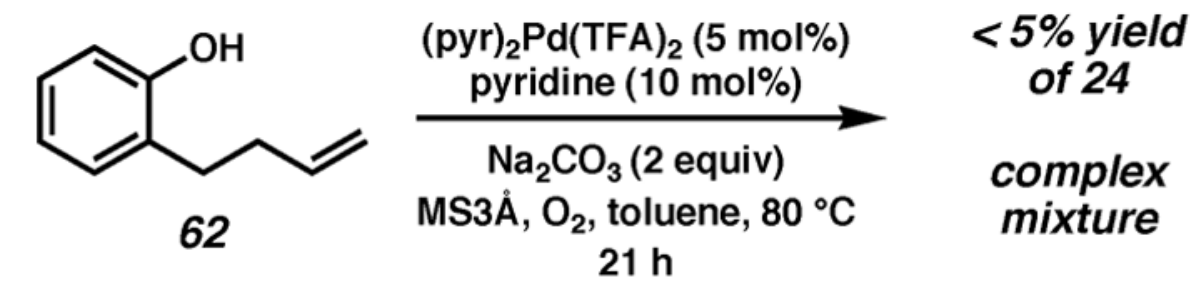

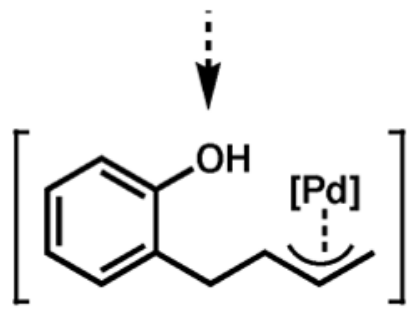

64

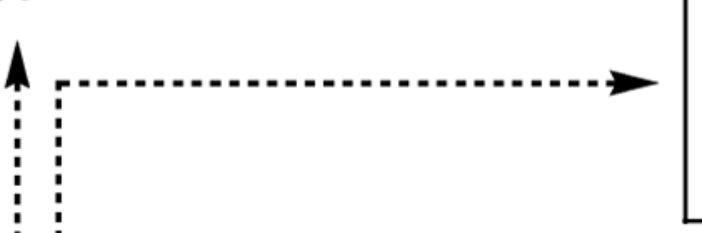

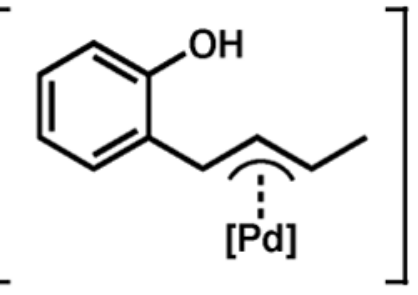

63

not productive for 24

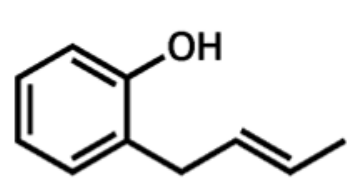

(pyr) ${ }_{2} \mathrm{Pd}(\mathrm{TFA})_{2}$ (5 mol\%) pyridine (10 mol\%)

$\mathrm{Na}_{2} \mathrm{CO}_{3}$ (2 equiv)

23

MS3Å, $\mathrm{O}_{2}$, toluene, $80^{\circ} \mathrm{C}$<smiles>C=CC1Cc2ccccc2O1</smiles>

$3 \mathrm{~h}, 74 \%$ yield

Scheme 3.

Attempted cyclization of a terminal olefin-appended phenol. 


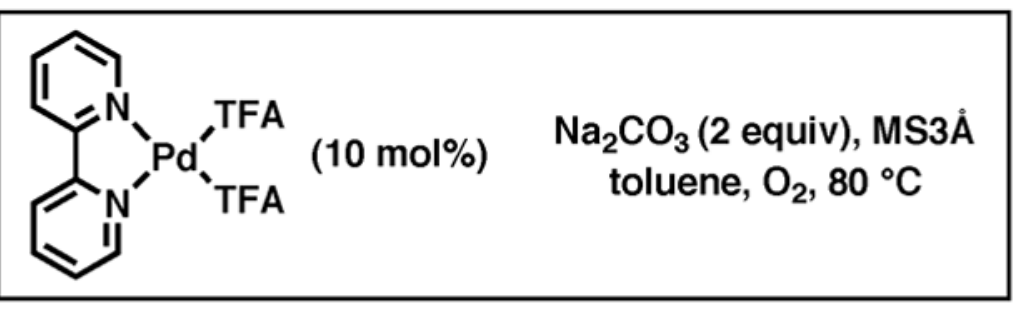

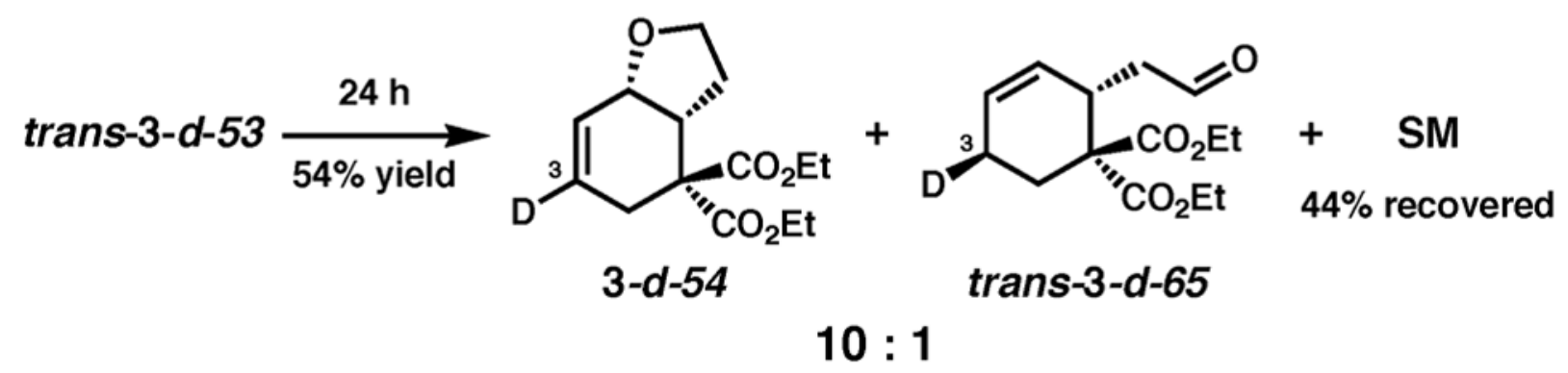<smiles>CCOCC1(COCC)[C@H](CC=O)C=C[C@@H]2OCC[C@@H]21</smiles>

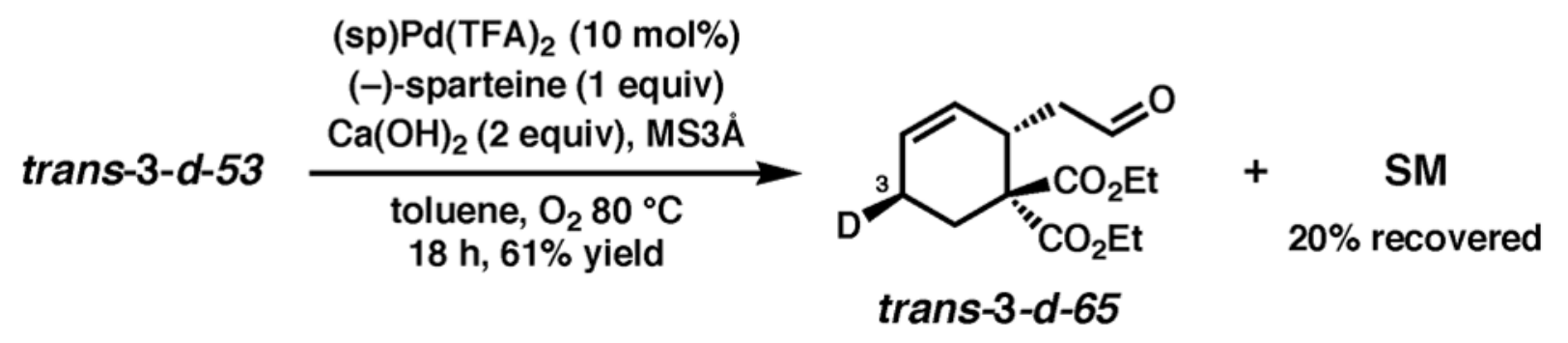

Scheme 4.

Cyclization of deuterium-labeled primary alcohol substrates with dipyridyl as ligand. 
A

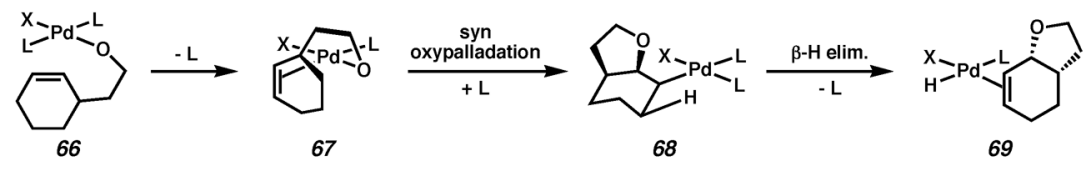

B

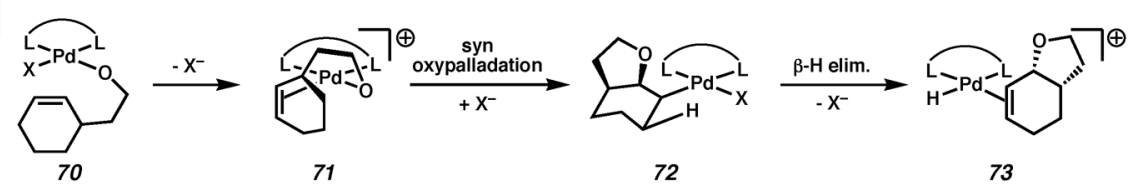

Scheme 5.

Comparison of reaction pathways with a monodentate and bidentate ligand. 


$$
\left(\begin{array}{cc} 
& \begin{array}{c}
\text { pyridine }(20 \mathrm{~mol} \%) \\
\mathrm{Na}_{2} \mathrm{CO}_{3}(2 \text { equiv), } \mathrm{MS} 3 \AA \\
\text { toluene }, \mathrm{O}_{2}, 80^{\circ} \mathrm{C}
\end{array}
\end{array}\right.
$$<smiles>[R9][C@H]1C=C[C@@H](CC(=O)O)[C@](COCC)(C(=O)OCC)C1</smiles>

trans-3-d-74<smiles>[2H][C@H]1C=C[C@H](CC(=O)O)C(COCC)(COCC)C1</smiles>

cis-3- $d-74$<smiles>CCOC(=O)C1(C(=O)OCC)CC=C[C]2OC(=O)C[C@@H]21</smiles>

$+\quad$ SM $34 \%$ yield<smiles>[2H]C1=C[C]2OC(=O)C[C@H]2[C@](COCC)(C(=O)OCC)C1</smiles>

3-d-75

Scheme 6.

Cyclization of deuterium-labeled carboxylic acid substrates with pyridine as ligand. 
Table 1

Optimization of Pd Source.

\section{Table 1}

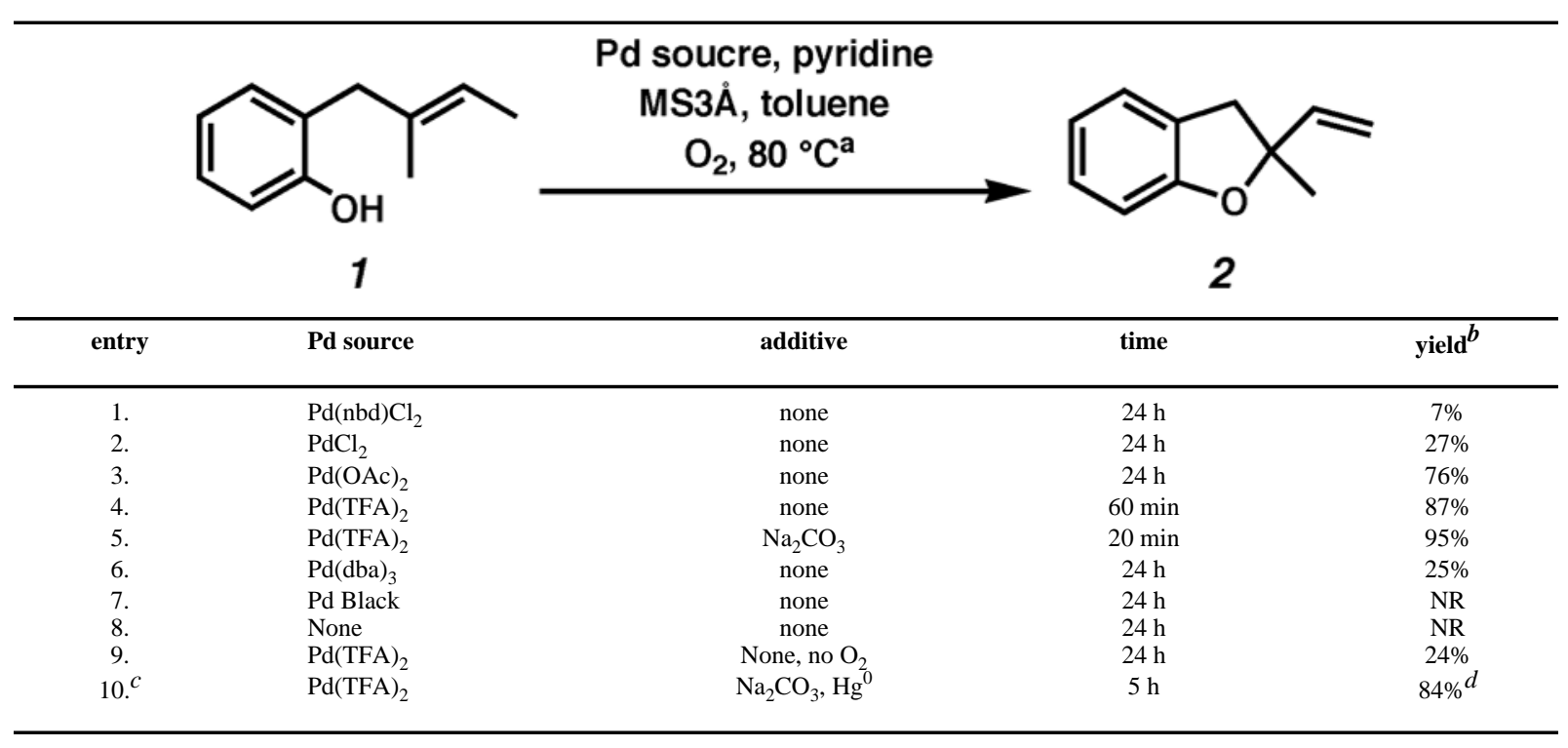

$a_{5 \mathrm{~mol}} \%$ Pd source, $20 \mathrm{~mol} \%$ pyridine, $500 \mathrm{mg} / \mathrm{mmol} \mathrm{MS} 3 \AA$, $1 \mathrm{~atm} \mathrm{O} 2$, toluene $(0.1 \mathrm{M}), 80^{\circ} \mathrm{C}$.

$b_{\text {Isolated yield. }}$

${ }^{c} 5$ mol $\%$ (pyridine) $2 \mathrm{Pd}(\mathrm{TFA}) 2,10 \mathrm{~mol} \%$ pyridine, 2 equiv $\mathrm{Na}_{2} \mathrm{CO}_{3}, 30$ equiv $\mathrm{Hg}^{0}$.

${ }^{d}$ Conversion determined by GC. 


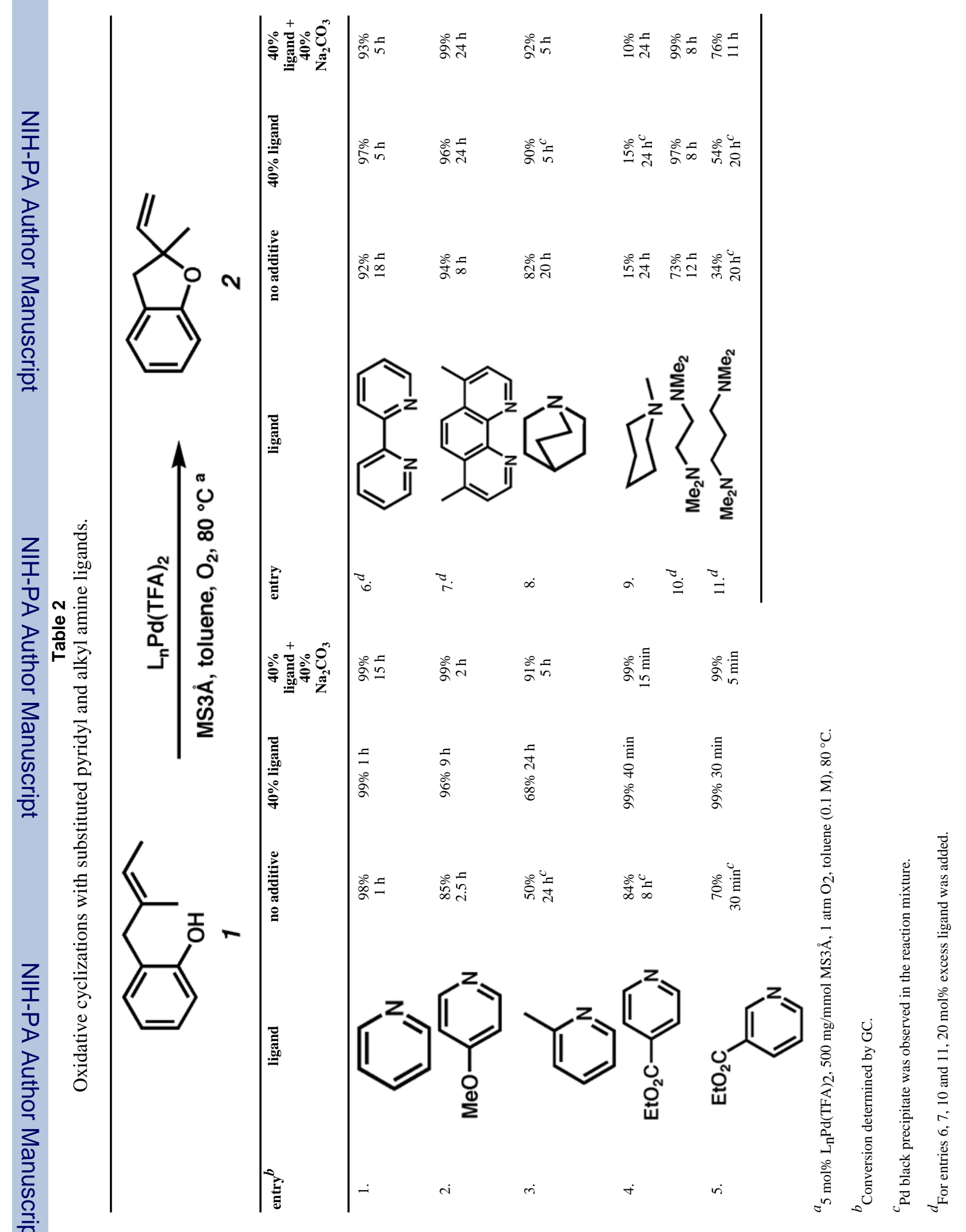


Trend et al.

Page 24

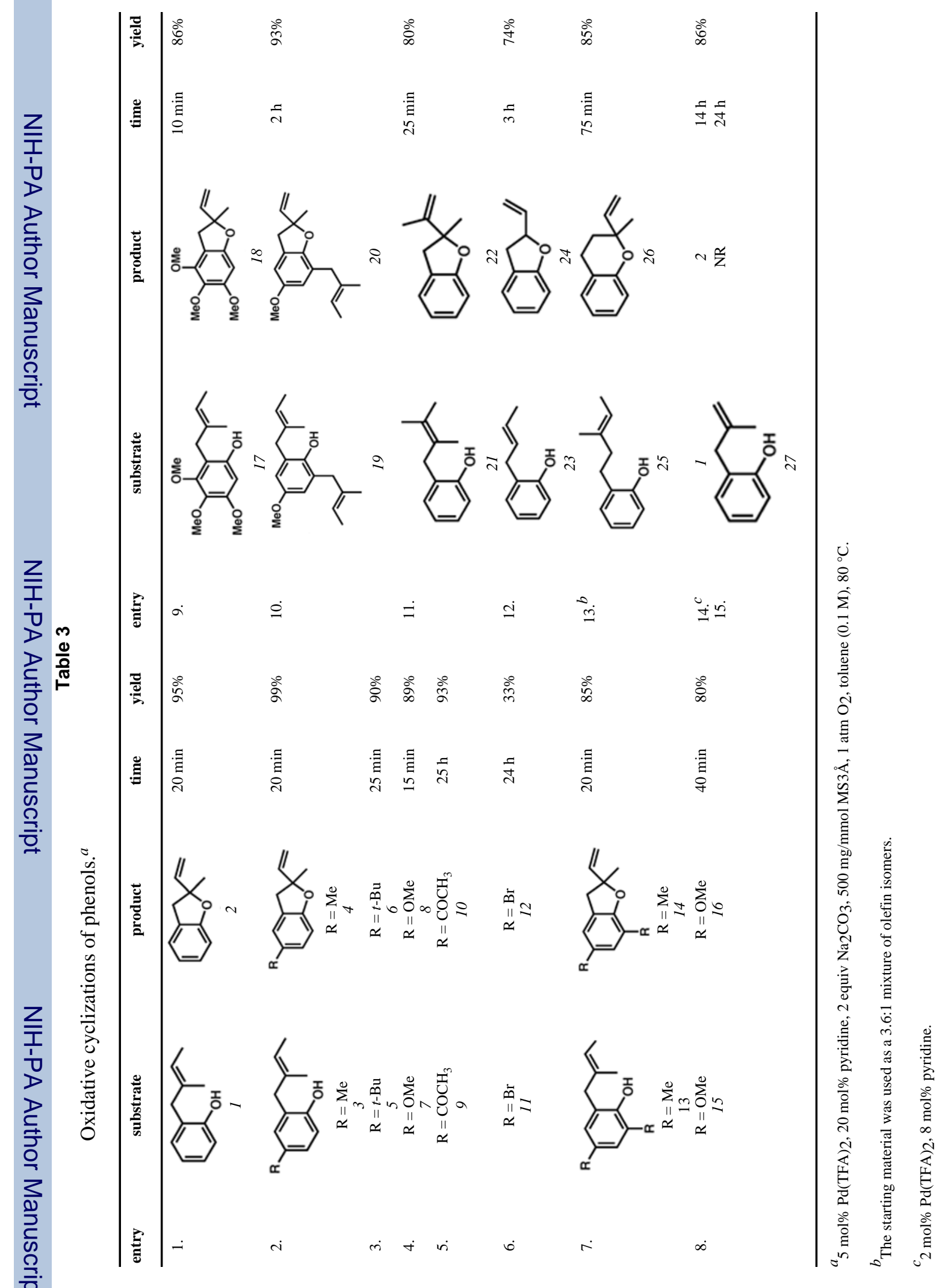

J Am Chem Soc. Author manuscript; available in PMC 2008 November 21. 
Table 4

Oxidative cyclizations of primary alcohols. ${ }^{a}$

entry substrate

\footnotetext{
$a_{5 \mathrm{~mol}} \% \mathrm{Pd}(\mathrm{TFA})_{2} 20 \mathrm{~mol} \%$ pyridine, 2 equiv $\mathrm{Na}_{2} \mathrm{CO}_{3}, 500 \mathrm{mg} / \mathrm{mmol} \mathrm{MS} 3 \AA$, 1 atm O 2 , toluene $(0.1 \mathrm{M}), 80^{\circ} \mathrm{C}$.

${ }^{b}$ The starting material was used as a mixture of $\mathrm{E}$ and $\mathrm{Z}$ olefins.

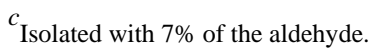

$d_{\text {Isolated with } 7 \% \text { of an olefin isomer. }}$

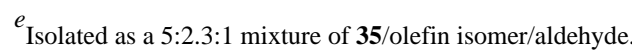


Table 5

Oxidative cyclizations of carboxylic acids and derivatives. ${ }^{a}$

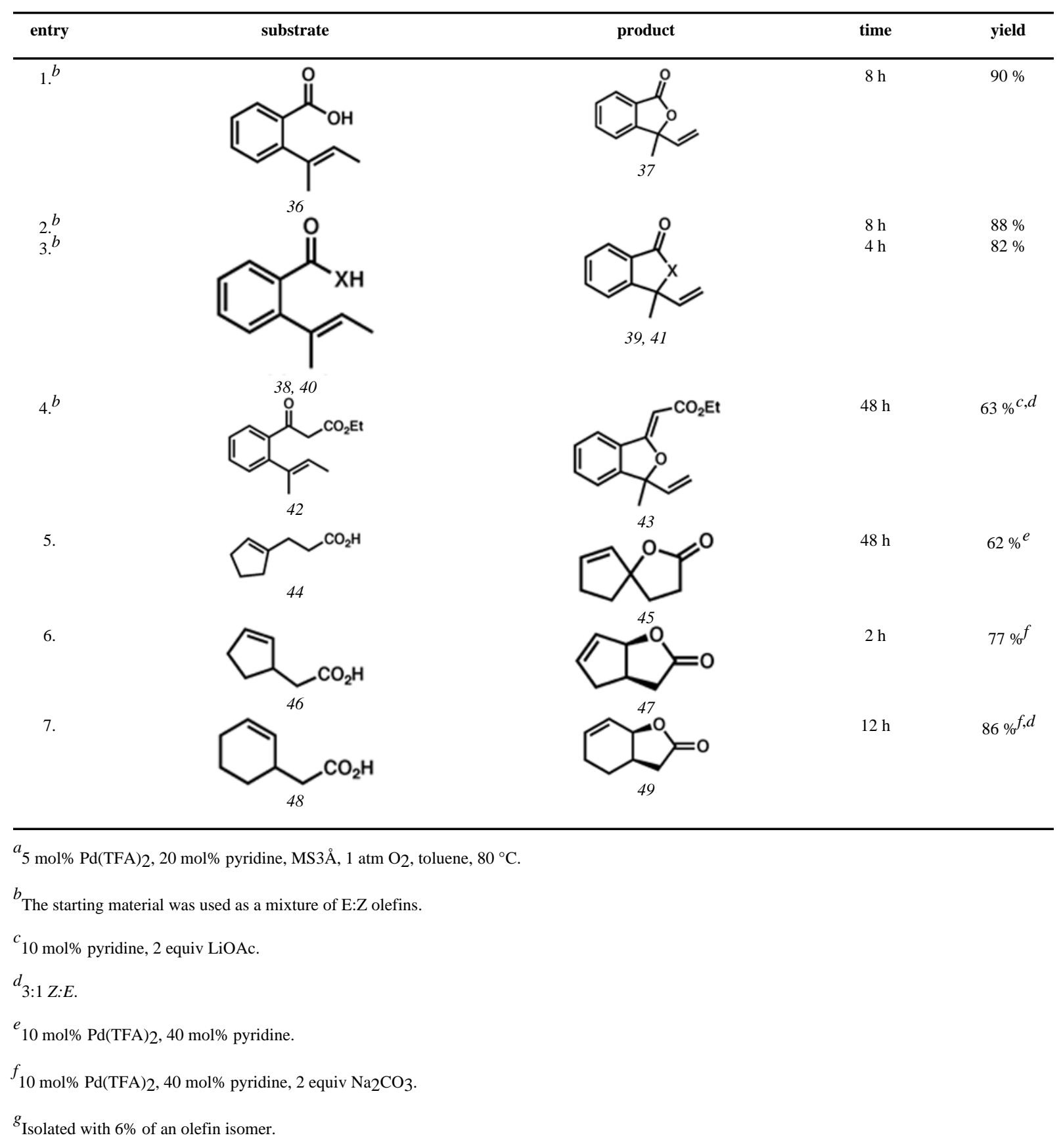


Trend et al.

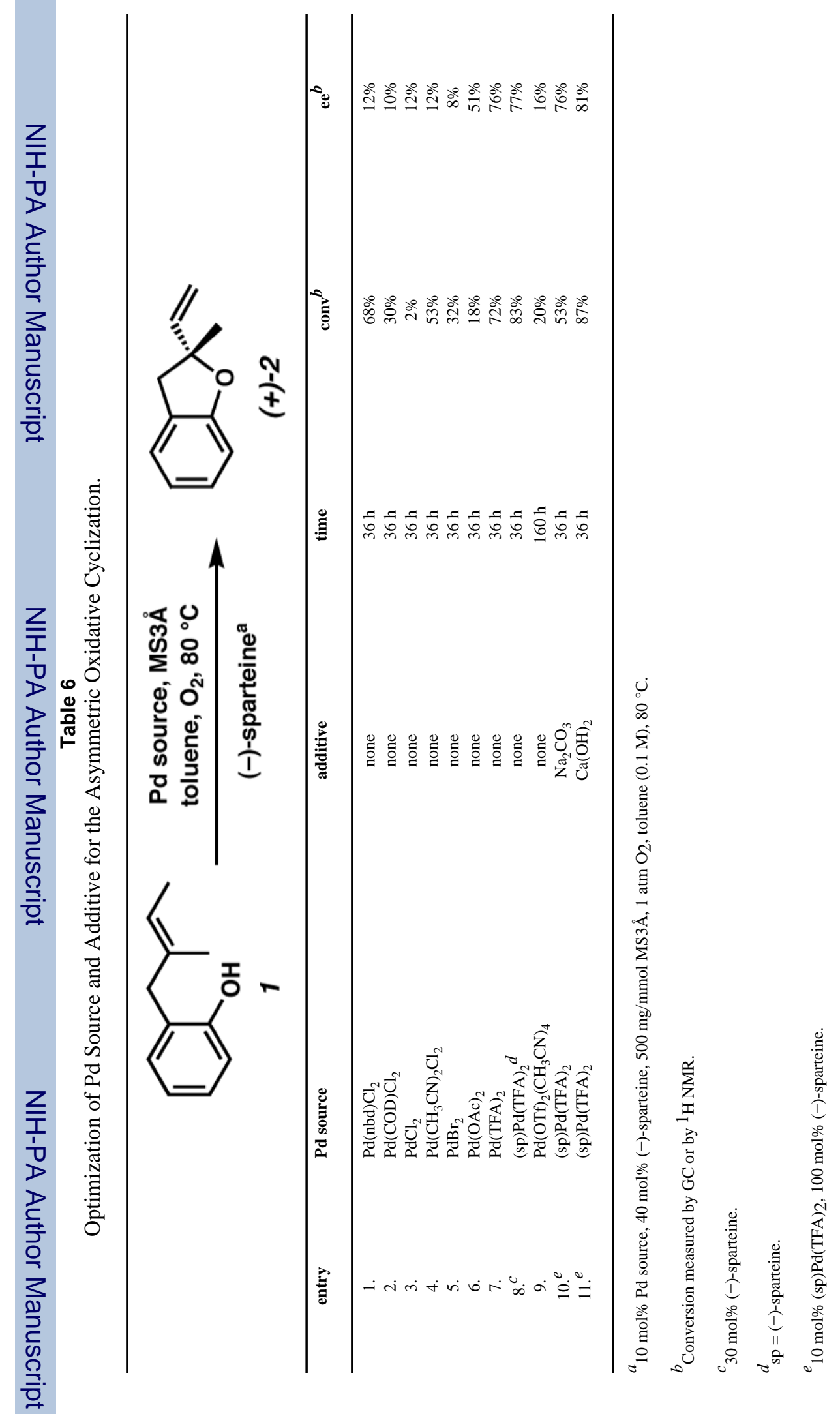




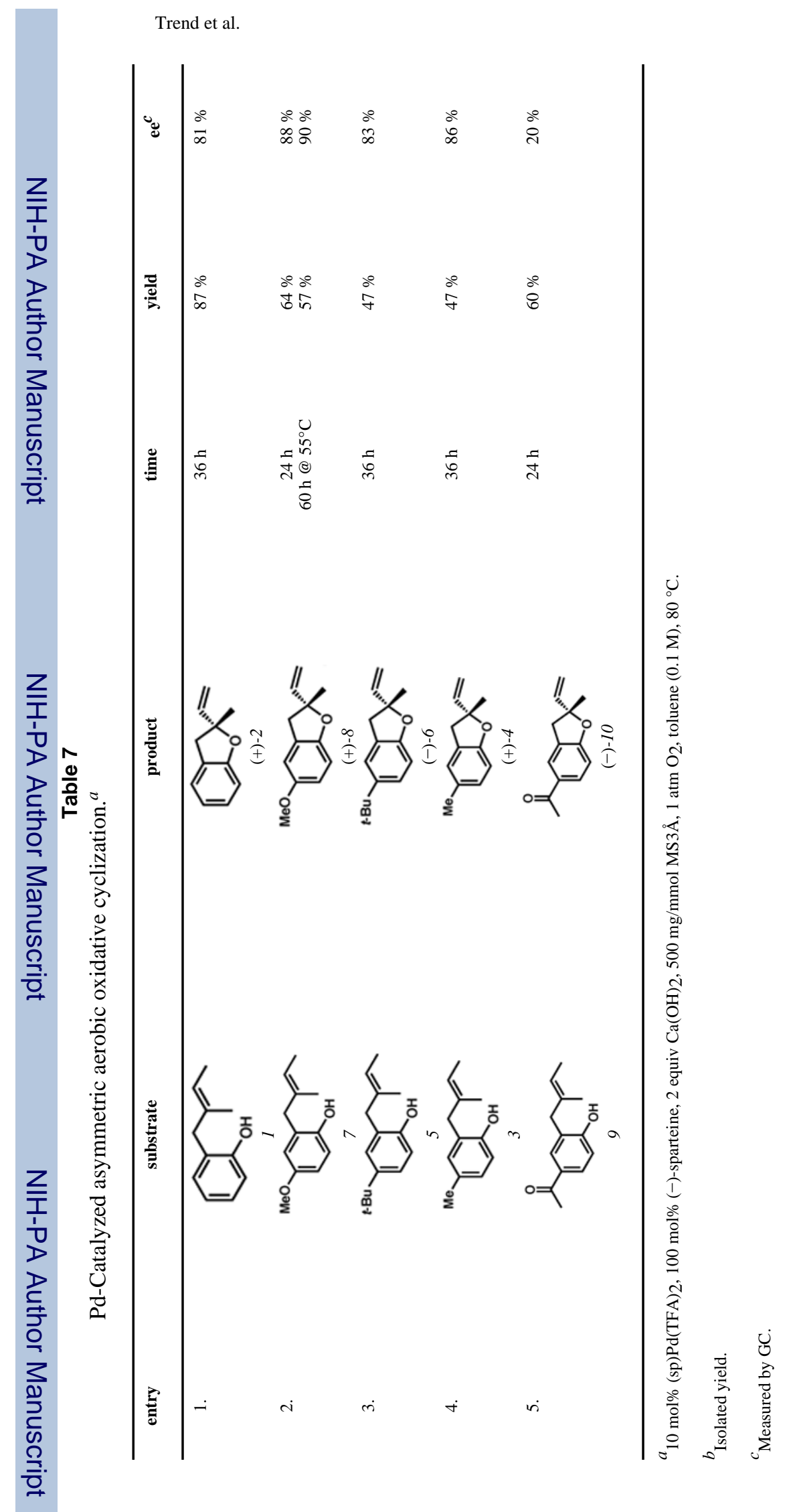

$J$ Am Chem Soc. Author manuscript; available in PMC 2008 November 21. 
Table 8

Aryl ether formation and attempted suppression.

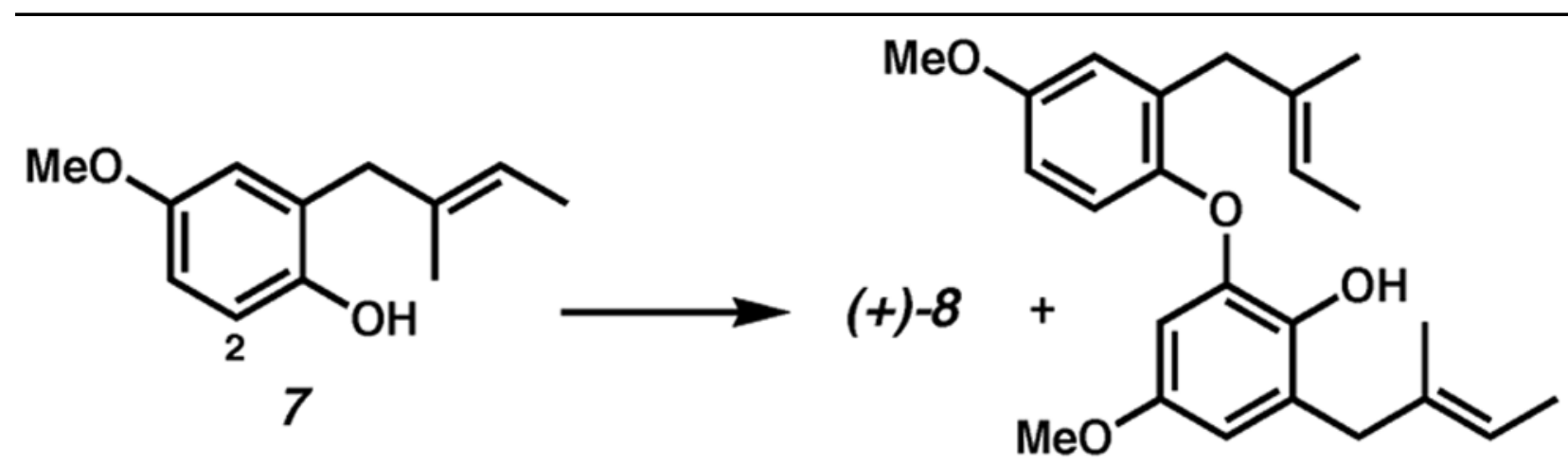

\begin{tabular}{|c|c|c|c|c|}
\hline entry & substrate & time & $(+)-8: 50^{b}$ & ee of $(+)-8^{c}$ \\
\hline 1. ${ }^{a}$ & amberlyst 15 resin $(10 \mathrm{~mol} \%)$ & $24 \mathrm{~h}$ & $5: 3$ & $87 \%$ \\
\hline 2. & $\mathrm{TsOH} \cdot \mathrm{H}_{2} \mathrm{O}(10 \mathrm{~mol} \%)$ & $24 \mathrm{~h}$ & $3: 1$ & $81 \%$ \\
\hline 3. & $\mathrm{TsOH} \cdot \mathrm{H}_{2} \mathrm{O}(100 \mathrm{~mol} \%)$ & $80 \mathrm{~h}$ & $6: 1$ & $50 \%$ \\
\hline 4. & none & $16 \mathrm{~h}$ & $2: 1$ & $86 \%$ \\
\hline
\end{tabular}

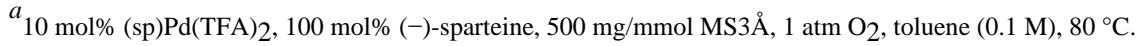

${ }^{b}$ Measured by ${ }^{1} \mathrm{H}$ NMR.

${ }^{c}$ Measured by GC. 